A war is forever: The long-run effects of early exposure to World War II on trust

Pierluigi Conzo, Francesco Salustri

PII:

DOI:

Reference:

To appear in:

Received date:

Accepted date:
S0014-2921(19)30165-5

https://doi.org/10.1016/j.euroecorev.2019.103313 EER 103313

European Economic Review

30 December 2018

29 August 2019

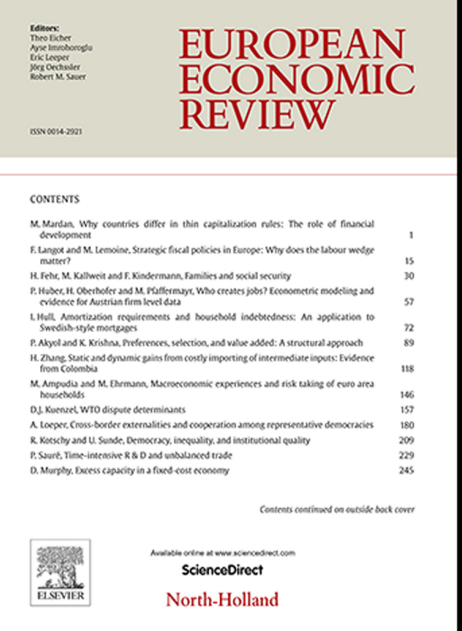

Please cite this article as: Pierluigi Conzo, Francesco Salustri, A war is forever: The long-run effects of early exposure to World War II on trust, European Economic Review (2019), doi: https://doi.org/10.1016/j.euroecorev.2019.103313

This is a PDF file of an article that has undergone enhancements after acceptance, such as the addition of a cover page and metadata, and formatting for readability, but it is not yet the definitive version of record. This version will undergo additional copyediting, typesetting and review before it is published in its final form, but we are providing this version to give early visibility of the article. Please note that, during the production process, errors may be discovered which could affect the content, and all legal disclaimers that apply to the journal pertain.

(C) 2019 Elsevier B.V. All rights reserved. 


\title{
A war is forever: \\ The long-run effects of early exposure to World War II on trust*
}

Pierluigi Conzo ${ }^{\dagger}$
Francesco Salustri ‡

September 2019

\begin{abstract}
This paper examines the long-term effect of conflict on trust by using changes in places and timing of combats during World War II. We focus on the pre-school period, an important life stage for the formation of trust and an age where war exposure may persist throughout life. We find robust evidence that individuals exposed to combats in the first six years of life display lower trust and social engagement well into adulthood. In light of the well-known relationship between trust and collective action, our results lend credence to the theory that violent conflict inhibits well-functioning government in long run.
\end{abstract}

Keywords: Trust, World War II, Childhood experiences, Conflict, Social preferences.

JEL Classification: D74; 015; 017; A13; J13; N44

Declarations of interest: none

\footnotetext{
* We thank Richard Akresh, Peter Arcidiacono, Charlie Becker, Alessandra Cassar, Giacomo De Luca, Marina Della Giusta, Glen Elder, Christopher Flinn, Steven Haas, Joe Heinrich, David Hugh-Jones, Hendrik Juerges, Ian Levely, Giovanni Mastrobuoni, Marjorie McElroy, Juan Morales, Luigi Pascali, Seth Sanders, Alessandro Tarozzi, Lowell Taylor and Duncan Thomas for their useful comments and suggestions. We also thank Compagnia di San Paolo (Turin) for the financial support to the project 'InsideTrust' (PI: P. Conzo).

† Corresponding author. Main affiliation: University of Turin (IT). Secondary affiliation: Collegio Carlo Alberto (IT). Address for correspondence: Dept. of Economics and Statistics "S. Cognetti de Martiis", University of Turin - Campus Luigi Einaudi, Lungo Dora Siena 100A, 10153, Torino, Italy. Email: pierluigi.conzo@unito.it

₹ Health Economics Research Centre, Nuffield Department of Population Health, University of Oxford, UK. Email: francesco.salustri@ndph.ox.ac.uk
} 


\section{Introduction}

Throughout the 20th century and into the 21st century there has been widespread violent conflict as a means of resolving political differences within and among countries. Two world wars before mid-century, proxy conflicts spurred on by Cold War tensions from the 1950s to the late 1980s and armed conflicts among political, religious, and ethnic groups since the 1980s have taken the lives of millions of people and lead to massive displacement of populations often based on ethnic distinctions.

Even after the violence stops, countries are plagued by dysfunction, much of which appears tied to an inability to form effective governments. According to the World Bank's statistics, almost all post-conflict countries show relatively weak performance in governance, which can last for many decades (Collier and World Bank 2003; Rondinelli 2007). In addition to the destruction of physical capital, state fragility is often associated with the decrease in social capital resulting from the erosion of cooperation and trust among the victims of a conflict (Rohner et al. 2013; Cassar et al. 2013; Becchetti et al. 2014; Kijewski and Freitag 2016). Not only do citizens of post-conflict areas appear less willing to trust each other, but also they tend to have lower levels of trust in institutions and more pessimistic beliefs about politicians' morality (Voors and Bulte 2014; De Juan and Pierskalla 2016). This might further hinder political participation and politicians' accountability, thereby exacerbating political inefficiencies.

A contrary view posits that societies affected by unprecedented conflicts might be able to return to pre-war levels of labor, capital and institutional quality in a relative short time (Tilly and Ardant 1975; Davis and Weinstein 2002; Miguel and Roland 2011), and to high levels of trust as well. Recent research shows that pro-social behaviour and political engagement increased in post-war communities (Bellows and Miguel 2006 and 2009; Blattman 2009; Voors et al. 2012, Bauer et al. 2017), mainly because affected individuals relied on mutual cooperation as a form of social insurance (Bauer et al. 2016), developed in-group favouritisms in social interactions (Putnam et al. 2004; Bauer et al. 2014a), or because the conflict enhanced social cohesion (Gilligan et al. 2014). This evidence is consistent with psychological research on some specific conflicts where groups exposed to violence - e.g. the Jewish Holocaust survivors (Carmil and Breznitz 
1991) and the Palestinians exposed to the first Intifada (Barber 2009) - appear resilient and politically engaged (Masten 2001; Werner 2007; Forstmeier et al. 2009; Arpino et al. 2019).

In spite of the growing number of studies analysing post-war outcomes, 'the social and institutional legacies of conflict are arguably the most important but least understood of all impacts' (Blattman and Miguel 2010, p. 42). The lack of a general consensus on whether the outbreak of violence harnesses or destroys social capital can be explained by the fact that most studies have focused on a single (developing) country. Given that conflicts originate from country-specific political, economic and ethnic reasons, it is not surprising that studies differ in conclusions about the impact of violent conflict on social preferences. Furthermore, apart from Bauer et al. (2017) documenting long-term legacies of child soldiering in Northern Uganda, most studies have shown effects of war within a few years after the end of violence; the very long-term effects of a worldwide conflict, such as those carried forward over a lifetime, are still underexplored.

This study aims to bridge this gap by shedding lights on whether early-life exposure to combat leaves an enduring mark on social trust in Europe. Our contribution is twofold. First, we consider a large-scale conflict, i.e. the Second World War (WW2), to which European regions were exposed at different times. By comparing individuals from diverse socio-economic and institutional contexts, our study provides estimated impacts with higher external validity than previous results based on a single country. Second, we bring the life-course approach into the analysis of preference formation, and study if combat exposure in the childhood predicts social trust in the adulthood. By combining retrospective survey data with WW2 combat events, our identification strategy exploits variation in period-place of conflicts and of respondents' birth, allowing us to net out unobserved heterogeneity in regional characteristics.

Our results show a negative impact of early exposure to WW2 on trust in the adulthood, both at the intensive and extensive margin (months of exposure). A negative effect is found also on social engagement, which - jointly with trust - is known to be a relevant predictor of cooperation in social dilemma (Putnam 1993; Frey and Meier 2004; Gächter et al. 2004). Additional tests suggest that the effect of combat exposure is driven mainly 
by episodes of city captures (ending with surrender), rather than bombing or attacks. Selection on mortality, fertility and migration does not drive our findings, whereas the estimated effect of WW2 is robust when controlling for current and childhood socioeconomic conditions, and for other hardships including hunger, dispossession and absence of parents. Drawing from psychological research, we discuss the role of parental stress and responsive caregiving as main mechanisms driving our results.

Since the relationship between trust and collective action is well known (e.g. Putnam 1993; La Porta et al. 1997; Scholz and Lubell 1998; Ostrom 2000), our evidence on the persistent legacies of war on trust and social engagement lends credence to the theory that violent conflict itself may inhibit well-functioning government in the long term. In addition, by showing that the effects of early-life exposure to combat on pro-social preferences last a lifetime, this study also contributes to the economic literature that recognizes early childhood as a critical period for shaping non-cognitive skills, which might substantially influence later life human-capital outcomes (Cunha and Heckman 2007; Heckman et al. 2013). In this respect, adjusting for differences in socio-economic and health outcomes, our findings also suggest that two characteristics of the childhood environment, i.e. socio-economic status and presence of biological mother, positively predict trust in the adulthood. Furthermore, in line with well-established psycho-social studies, our results identify the critical period (i.e. age 0-6) in which exposure to shocks might produce long-lasting effects on trust.

\section{Background}

Social trust, or trust in other persons, could be defined as 'a person's belief that another person [...] will act consistently with their expectations of positive behaviour' (OECD 2017 , p. 42). From the behavioural point of view, a trusting person sends resources to another (unknown) person without any guarantee that these resources will be returned (e.g. Fehr 2009). From the attitudinal point of view, trust could be thought as the belief that other people will behave in a trustworthy way, and as the expectation about whether other people share the same fundamental values (Hardin 2004; Uslaner 2002). Trust is generally measured through survey questions or experimental games (Berg et al. 1995). In this paper, we rely on attitudinal trust as measured through the generalized 
trust question (GTQ) (Rosemberg 1956), which is widely used in economic research (e.g. Algan and Cahuc 2010; Tabellini 2010; Conzo et al. 2017; Murtin et al. 2018).1

Regarding the development of trust over the life-course, pre-school years are considered as a critical stage of life for the formation of enduring prosocial motivations and ingroup favouritism (Aboud 2003; Fehr et al. 2008; Eisenberg et al. 2006; Voigtländer and Voth 2015; Bauer et al. 2014b and 2017); they are also deemed an age where combat exposure may persist throughout life (Leon 2012; Currie and Vogl 2013). In this period of life children's trust is highly sensitive to traumatic experiences such as war events, which might generate psychological distress (Kijewski and Freitag 2016) and lead to the formation pessimistic beliefs about the trustworthiness of the others.

Since the seminal contribution by Erikson (1950), a prominent body of socialpsychological literature has emphasized that the stable components of preferences and attitudes are formed very early in life. Under this perspective, trust becomes an integral part of one's personality (Allport 1961; Cattell 1965; Rosenberg 1956; Uslaner 1999, 2002), which is developed through early childhood socialization and tends to change only slowly thereafter. During infancy and pre-schooling years children develop a sense of trust in oneself and in others and learn to relate themselves emotionally to parents, siblings, and other people.

Moreover, early childhood is considered an important phase for value development in the primary context of the family (Ainsworth and Bowlby 1991) since caregivers appear for young children as the key interfaces between the self and the others. Not only do parents serve as a source of information, judgment, and filter on the external world, but also they provide children with role models and emotional stability. In this perspective, the development of trust or mistrust in early childhood depends on the type of caregiving received (Erikson 1959), with trust emerging when infants experience responsive caregiving and develop a secure attachment bond with their parents (Bowlby 1979; Ainsworth and Bowlby 1991); mistrust would result instead from harsh treatments or tardive responsiveness (Erikson 1950; Crain 2005). Furthermore, the trust formed in the early childhood through the interaction with caregivers may persist

\footnotetext{
1 The GTQ asks: 'Generally speaking, would you say that most people can be trusted, or that you can't be too careful in dealing with people? ( 0 = you can't be too careful; 10 = most people can be trusted)'. Answers to this question are shown to be correlated with experimental measures of trustworthiness (Glaeser et al. 2000), expected trustworthiness and altruism (Sapienza et al. 2013; Murtin et al. 2018).
} 
throughout life, and predict social functioning well in the adulthood (Waters et al. 1995). ${ }^{2}$

Against this backdrop, children in pre-school age are highly vulnerable to wartime violence and destruction (Arroyo and Eth 1996; Pynoos and Nader 1993), which create in them a sense of confusion and self-blame. These reactions might be amplified when caregivers are perceived as stressed and overextended because of the traumatic events. In those cases, parents might be unable to foster secure attachment and to instil the belief that unknown others, in general, can be trusted. Moreover, anxiety caused by frequent war episodes may increase parents' emotional instability and poor (perceived) parenting (Punamäki et al. 1997). For instance, lack of food or job opportunities require parental investment of time, physical and cognitive resources in coping strategies, which are implemented often outside the household. In this regard, Burlingham and Freud (1942) offer real-life examples of how parental behavior during WW2 might amplify or buffer against the traumatic effects of the war on pre-school children. The authors report a series of psychological observations made at the residential war nurseries in London during WW2, and document that in most cases children under five years are little affected by bombing, provided they were not injured, they were in their mother's care and their mother showed no signs of panic.

All these studies motivate our analysis by emphasizing that the traumatic events witnessed directly (through personal traumatization) or indirectly (through parents' reactions to war events) during the initial years of life might produce enduring effects on trust.

From a methodological point of view, our paper is closely related to the studies showing the negative effect of WW2-exposure on health outcomes (Kesternich et al. 2014; Havari and Peracchi 2016). These studies rely on an objective victimization measure capturing a broad effect of societal/cohort exposure to war. They consider also Europeans born after the war, and implicitly assume that for these individuals living in a region of conflict during WW2 has the same effects as living in a non-conflict region. This might not be a plausible assumption in our case since trust and social engagement in a war

\footnotetext{
2 The mentioned studies represent a well-established strand of literature in psychology as signaled, for instance, by the number of citations: Erikson (1950), 40662 citations; Erikson (1959), 11196 citations; Allport (1961), 7041 citations; Bowlby (1979), 4586 citations; Ainsworth and Bowlby (1991), 2027 citations (Google Scholar data, July 2018).
} 
area may influence the beliefs of individuals growing up in that area also after the end of the war. Finally, since Kesternich et al. (2014)'s measure of war exposure varies at regional level, unobserved regional characteristics could lead to a spurious correlation between victimization and later outcomes. ${ }^{3}$

By exploiting between- and within-region variation in combat exposure, our approach instead allows to net out regional features. This is a substantial improvement since levels of trust are shown to be very heterogeneous across EU regions (Tabellini 2010), though stable in time (Volken 2002; Dohmen et al. 2012). Moreover, since we also compare exposed vis-à-vis non-exposed individuals who lived in the same region when conflict episodes occurred, unobserved heterogeneity in how WW2 affected local institutions and post-war recovery would not bias our estimates.

Closely related to our study, Ichino and Winter-Ebmer (2004) show that the individuals living in Germany and Austria who were ten years old during WW2 turn out to be less educated than the same cohort living in Switzerland and Sweden (non-war countries). With respect to social preferences, Kesternich et al. (2018) show that the hunger suffered by the young German cohorts born after WW2 in response to calorie restrictions policies had detrimental effect on trust levels in the adulthood.

We build on these results by including individuals living in a large set of EU regions who were differentially exposed to war episodes depending on their month and place of birth. A similar approach is followed by Bundervoet et al. (2009) and Akresh et al. (2012), who document short- and long-term effects of civil war on health, respectively in Nigeria and Burundi. In the same spirit, but limited to Germany, Akbulut-Yuksel (2014) exploit the region-by-cohort variation in the intensity of WW2 to assess the long-term consequences of the war on human capital and labour market outcomes. Instead of considering birth-year cohorts as in Bundervoet et al. (2009) and Akbulut-Yuksel (2014), we compare individuals born in different months during WW2, and in different regions where conflicts occurred. Hence in our analysis the length of exposure (months

\footnotetext{
${ }^{3}$ The authors control for country fixed effects. However, while indeed helpful, this is not sufficient to mitigate unobserved heterogeneity. First, country borders changed frequently during WW2 and it is therefore difficult to identify common country characteristics during the years of the war. Moreover, it is not clear whether they control for the country of residence during WW2 or at the time of the interview. Second, individuals in conflict regions might have moved to non-conflict areas during and after the war. It is therefore difficult to assign to each individual a unique country dummy during and after the years of the war. Third, trust varies substantially within-countries (as also other socio-economic characteristics do), and country fixed-effects do not fully account for this source of heterogeneity.
} 
of war) depends both on the timing and location of each war episode as well as on the (plausibly exogenous) respondent's month-year and place of birth.

However, in spite of the recognized importance of trust for societal success, little is known about how persistent are adverse early-life circumstances on trust over the life course, and what are the childhood or adulthood characteristics that act as mediators or moderators. This paper aims to fill this gap by providing causal evidence on how exposure to a massive shock hitting a multiplicity of societies at different stages of development (Europe before 1939) influenced later-life trust of their citizens, and check if and in which direction individuals' life history played a role.

\section{Data}

We use two sources of data. The first is the Survey on Health, Ageing, and Retirement in Europe (SHARE), which is a rich and multidisciplinary database that collects sociodemographic and health information of Europeans aged above 50. More specifically, we use wave two and five, which include a specific question on generalized trust as well as a large set of socio-demographic characteristics. Wave 2 was administered from 20062007, while wave 5 in 2013. Trust is assessed on an eleven point-scale answer to the question 'Generally speaking, would you say that most people can be trusted or that you can't be too careful in dealing with people? $(0=$ you can't be too careful; $10=$ most people can be trusted)'. ${ }^{4}$ We merge these data with the life-course events retrospectively retrieved from the third wave of SHARE (SHARELIFE).

SHARELIFE focuses on past life events of respondents including the regions where they lived and the characteristics of their childhood, which provide us with a measure of their socio-economic status (SES) during the childhood (Havari and Peracchi 2016). These data allow us to identify the regions where respondents lived when they were born, and the year in which they move (if they did). In order to mitigate potential bias due to selective migration, we restrict the sample to individuals born during WW2 who never moved to other regions. However, in the econometric analysis we relax this restriction

\footnotetext{
${ }^{4}$ Results are robust if we use as dependent variable trust standardized by country or overall (available upon request).
} 
and consider also people who migrated during the war period. ${ }^{5}$ The reliability of retrospective data contained in SHARELIFE has been proved by Havari and Mazzonna (2015), who document the internal and external consistency of self-reported measures of childhood health and SES.

The second source of data hinges on the original and detailed description of combat events during WW2, including battles, attacks, bombings, invasions, and occupations by Ellis (1994), Davies (2006) and Collier (2004). The dataset we have generated from these historical sources includes major bombing and minor attacks at regional level and in each month between September 1939 and September $1945 .^{6}$

Finally, we combine information on the month and year of birth, the region where respondents lived during the war, and the war events that occurred in each year and month in each region to create a measure of WW2 exposure (War). This variable captures the number of months each respondent experienced war conflict where they lived between September 1939 and September 1945. More specifically, War assigns the cumulative number of months $x \in\{0,1, \ldots, \mathrm{n}\}$ of exposure to combat if at least one conflict occurred during a month in the region the respondent lived as a child. For instance, Sicily was affected by the Allied invasion. This consisted of several events ranging from territorial occupation, aerial bombing, assaults, military advances, and city captures that occurred over four months between June - September 1943; then, War records four months of events for the respondents born in June 1943 or before, three months for those born in July 1943, two months for those born in August 1943, one month for those born in September 1943, and zero for all the respondents born after September 1943.

More generally, Figure 1 shows an example for three hypothetical individuals (A, B, and C) that, despite growing up in a region experiencing six war events (distributed over three months), are differentially exposed to combat because of their month of birth. Individual A experienced three months of combat, e.g. May 1940, June, and July 1942, and therefore her War variable takes value of three. Analogously, individual B

\footnotetext{
${ }^{5}$ Geographical information is collected at NUTS2-level.

${ }^{6}$ We consider the beginning of the war on September 1939, when Germany occupied Poland, and the ending of the war on September 1945, when the formal Japanese surrender was signed. Results are robust when restricting the analysis to May 1945 (available upon request).
} 
experienced two months of combat since (s)he was born after the first war event in the region that occurred on May 1940. Her War variable is therefore equal to one. Finally, for individual C the War variable is equal to zero since (s)he did not experienced any war event. Hence respondents who grew up in the same region but were born in different months have also a different length of exposure to WW2.7

To exploit within-region variation in exposure stemming from different months of birth and, at the same time, focus on the childhood years that are deemed critical for the formation of trust, we consider only respondents born between September 1939 and September 1945; hence they would be at most six years old when WW2 officially ended. We measure the effect of combat exposure both at the extensive and intensive margin. ${ }^{8}$ First, we create an indicator variable for individuals who experienced at least one episode of conflict. This variable (War 0-1) is equal to one if the respondent was born at least one month before a conflict episode (in a region where the episode occurred), and zero otherwise. Second, we create a categorical variable taking value zero for no exposure, one for one to three months of exposure and two for more than three months of exposure. This variable (War 0-2) captures the plausibly exogenous variation in length of WW2-exposure induced by different birth periods also in case of individuals living in a region exposed to frequent combats.

Our dataset includes Austria, Germany, Sweden, The Netherlands, Italy, Spain, France, Denmark, Greece, Switzerland, Belgium, Czech Republic, and Poland. ${ }^{9}$ While consistent with the psychological literature considering exposure at pre-school age as crucial, the analysis of the WW2 by months of conflicts for respondents born during 1939-1945 allows us to explore within-region variation and net out region-fixed effects; it allows also to isolate the effect of the WW2 from that of other wars that ended before

\footnotetext{
${ }^{7}$ Note that if a war event occurred in region $x$ in a specific day, e.g. May 1st 1940, we consider one more month of exposure for all respondents born in May 1940 and before, provided that they lived in region $x$ in 1940. Moreover, if multiple events occurred in the same month in a region, we consider them as a single episode of war, and therefore as one month of war. SHARE data does not distribute residential information at a lower level than the region. For this reason, we cannot assign WW2-episodes occurring in a city to respondents who were living in that city at the time of the war. However, if a war episode occurring miles away from a respondent's house produced a significant effect on his/her trust, our estimate can be considered as the lower bound of the true effect.

${ }^{8}$ Notice that our measure of combat exposure does not necessarily capture the strength of combat exposure per country per se, but the exposure to combats and bombing.

${ }^{9}$ As a robustness check we excluded countries that were not involved in WW2, i.e. Spain, Switzerland, and Denmark (for these countries the war-exposure measure takes value of zero). Results are robust to this restriction and available upon request.
} 
September 1945, e.g. the Spanish Civil War and the German occupation of Czech Republic.

\section{Descriptive evidence}

Table 1 shows descriptive statistics of the main variables used in the econometric analysis (see variable legend in Appendix, Table A1). The average level of trust is 5.8 and 39 percent of the sample was exposed to at least one conflict episode during WW2. The fraction of respondents exposed to one to three months of war is 19 percent, while 20 percent of the sample experienced more than three months of war. The sample is balanced in terms of gender (54 percent are women), with most individuals being married (74 percent), retired (73 percent) and with no or primary education (29 percent).

In order to measure respondents' socio-economic status during the childhood, we extract the first factor from a principal component analysis (PCA) aimed at capturing latent family traits at the age of ten. As in Havari and Peracchi (2016), the PCA includes the number of rooms, the number of books at home and the main occupation of the breadwinner. In Figure 2A we compare the distribution of SES in childhood by combat exposure. The two distributions almost perfectly overlap, highlighting that there are no significant differences in SES at the age of ten between respondents exposed vs. nonexposed to war episodes. A comparison of average SES in childhood by combat exposure and semester of birth shows that the main difference in SES is among respondents who were older during the war, i.e. those born in 1939 (Figure 2B). The average difference in childhood SES between exposed and non-exposed starts decreasing from 1940 onwards and, apart from the last quarter of 1940, the SES trend for the two groups looks similar. We also run a set of non-parametric tests to check for systematic differences between respondents exposed and not exposed to WW2 in terms of other characteristics. Results show no significant differences in demographic characteristics (Table A2a in Appendix). Exposed respondents, however, display on average inferior health and economic outcomes, suggesting that our identification strategy perfectly replicates previous results on the negative impact of WW2 on many human capital dimensions (AkbulutYuksel 2014; Kesternich et al. 2014; Havari and Peracchi 2016). Childhood 
characteristics are in general balanced by combat exposure. As expected, exposure to combat is associated with poor health in childhood and lower chances of living with biological father at the age of ten as well as relocating and experiencing hunger during WW2. This evidence suggests that such childhood circumstances can be potential ways through which the war influenced individual's lives and also on their trust levels.

In Table A2b in Appendix, we report country-level statistics on WW2 exposure. Germany and Czech Republic appear as the countries where the intensity of WW2 was the highest and lowest respectively in terms of average months of exposure and share of population that died during the war.

Generalized trust is on average significantly higher for respondents who were not exposed to conflict (Figure 3A). Comparing average levels of trust over semesters of birth, non-exposed respondents systematically report higher trust than exposed respondents, while - as expected - the trends tend to convergence towards the end of the war (Figure 3B).

The maps in Figure 4A and 4B report respectively the geographical distribution of war episodes and the fraction of respondents who experienced at least one month of conflict during the childhood. Both maps highlight a substantial within-country variability in conflict magnitude and respondents' degree of exposure.

Overall this descriptive evidence suggests that individuals who did not experience war events early in life have higher trust levels in the adulthood than those who witnessed at least one war episode. This difference does not seem to mirror disparities in SES of the family of origin. However, third factors (e.g. SES in adulthood and war-related conditions in childhood) might be still driving the observed gap in trust. We account for these channels in the econometric analysis.

\section{Econometric analysis}

By exploiting variation in i) month-year of war episodes, ii) region where the latter occurred, and iii) month-year of birth of respondents during WW2, we assess the impact 
of being exposed to war episodes in early childhood (age 0-6) on later levels of trust. Our estimating equation writes:

$$
\text { Trust }_{i j t}=\alpha_{j}+\gamma_{t}+\beta_{1} W a r_{j t}+\sum_{k} \beta_{k} X_{k, j i t}+\varepsilon_{i j t}
$$

where Trust $t_{i t}$ is the value of generalized trust of individual $i$, born in period $t$ and living in region $j ; \alpha_{j}$ and $\gamma_{t}$ capture respectively region and month-year of birth fixed effects. The latter are estimated by including dummies for each month of birth of the individuals in each year, e.g.: Sept-1939, Oct-1939, ..., Sept-1941, Oct.-1941, ..., Sept.-1945. War je $_{j t}$ is either a (0/1) dummy variable for individuals who were exposed to at least one month of conflict, or a $(0 / 2)$ categorical variable capturing the differential effect of being exposed to war for shorter or longer periods. All specifications include a dummy for women (Female) and for wave of interview (Wave 5). In alternative specifications we also control for a set of $k$ socio-demographic variables $\left(X_{k, i j t}\right)$ including education level, income percentile, marital status, job status, health status, ${ }^{10}$ and memory performance (Memory). ${ }^{11}$

\subsection{Baseline results}

Results in Table 2 report OLS estimates of eq. 1, which suggest that exposure to combat during the childhood has a negative impact on trust in the adulthood. This effect is significant both at the extensive margin (column 1) and the intensive margin, though in the latter case only for longer exposure (column 2). Since the effect of exposure might be mediated by other factors (e.g. education, income, and health), we control for sociodemographic and economic characteristics measured at the time of the interview (columns 3 and 4). Results are robust, suggesting that the negative effect of early-life exposure to combat is not mainly driven by observable (and potentially unobservable) characteristics correlated with health, education and income in the adulthood. ${ }^{12}$

\footnotetext{
${ }^{10}$ Because SHARE contains several measures of individuals' health, we can include in our analysis i) the number of chronic diseases (n_chronic_diseases) reported by the respondent and ii) the first extracted component (health_functionalities) from a factor analysis on a set of the indices capturing mobility difficulties (see variable legend in Appendix, Table A1).

${ }^{11}$ Memory is the sum of scores from two recalling tasks. It contains the number of words recalled in a first trial of (and in a delayed) word recall task.

12 Results are robust when controlling for Body Mass Index, height and weight as measured at the time of the interview; results are also robust to the inclusion of specific childhood diseases (i.e. infectious
} 
Controlling for memory performance also mitigates measurement-error bias, which might be non-negligible when retrieving past information from aged respondents (we deal with recall bias and measurement error in Sections 1 and 3 in Appendix).

Finally, we check whether the trust gap between the exposed and the non-exposed narrows when controlling for events or characteristics that are specific to the respondents' childhood. We first test the mediating role of SES in childhood, which might also be thought as a proxy for parental investment in human capital (variable $S E S$ in childhood). Since trust levels tend to be high when personal or family-or-origin SES is also high (Gächter et al. 2004; Kesternich et al. 2018), the omission of childhood SES could lead to an upward bias in the estimated effect of combat exposure. Results are reported in Tables 3-4 and show that the significance and the magnitude of the war effect do not change remarkably (columns 1-2) while the effect of SES in the childhood is positive and significant as expected. ${ }^{13}$ Results in Table 3-4 also show that the war effect is generally robust to an alternative clustering of standard errors.

\subsection{The role of health, hunger and absence of parents}

Exposure to combat during childhood can lead to worse health outcomes later in life, because of, for instance, limited availability of food (Kesternich et al. 2014 and 2015; Havari and Peracchi 2016). Hunger and malnutrition might also have direct effects on trust as shown by Kesternich et al. (2018), who document that calorie restrictions for Germans born after WW2 lead to less trust in the adulthood because increased competition over scarce resources crowded out mutual trust. In addition, growing up without a parent might be both a consequence of WW2 and a possible determinant of trust since it may affect the emotional and cognitive development of children (TamisLeMonda et al. 2004) as well as their mental and physical health in the adulthood (Glaesmer et al. 2011; Werner 2012).

diseases, polio, asthma or respiratory problems, allergies, severe diarrhoea, meningitis, ear problems, difficulties in seeing, speech impairments). The war effect does not change when accounting for different measures of mental health at the time of the interview, i.e. depression, anxiety, self-assessed health, subjective life expectancy and optimism about future. These additional results are available upon requests.

${ }^{13}$ In order to test for the presence of heterogeneous effects of WW2 by childhood characteristics, we add (in an alternative specification) an interaction term between the war indicator and childhood SES. The coefficient of childhood SES and that of the war indicator remain significant, whereas the coefficient of the interaction term is positive but not statistically significant (results are available on request). This result suggests that high childhood SES does not counterbalance the adverse WW2-effect on trust. 
In order to test whether health, hunger and prolonged absence of a parent are the mechanisms underlying our results, we rely on respondents' retrospective data on health status, hunger episodes and the presence of a parent during the childhood, acknowledging the possible measurement error in those memory-based information. ${ }^{14}$ While health status in adulthood and childhood could absorb the indirect effects of hunger and parental absence, i.e. those passing on through poor health outcomes (Kesternich et al. 2014), controlling for parental absence and hunger episodes allows us to account for the direct influence these war-related circumstances may have on trust.

Besides adjusting for memory performance (memory), we discuss measurement error and recall bias in Appendix (Sections 1 and 3), and provide evidence suggesting that self-reported information match fairly well with historical facts.

Hence we include in the main regression the following variables: current number of chronic diseases; presence of a parent at the age of ten (mother at age 10; father at age 10); any hunger episode occurred during the war (hunger episode); self-assessed health status when child (health status in childhood); residence in a rural area during the childhood (rural area when child); any vaccination received at early age (vaccinated when child). Results are robust also to the inclusion of all these variables (columns 3 and 4 in Tables 3-4). As expected, those who grew up with the biological mother show higher trust than those who did not. This result underlines the importance of responsive childcare for the development of values at the early stages of life. ${ }^{15}$ In line with results by Kesternich et al. (2018), we find evidence of a negative impact of current and past health status on trust. Nevertheless, the effect of WW2 exposure remains significant and robust in magnitude, suggesting that health, hunger and father absence are not likely to be the main drivers of our results.

\footnotetext{
${ }^{14}$ The meta-study by Hardt and Rutter (2004) emphasizes that the measurement error in the retrospective account of traumatic childhood experiences might be non-random with respect to individual characteristics. Endogenous misreporting is also shown to explain the impact of combat exposure on civic and political engagement, whereby objective and self-reported measures of victimization lead to opposite results (Child and Nikolova 2016). See Sections 1 and 3 in Appendix for further analysis.

15 This variable may be an imperfect proxy for parental support in the childhood since respondents are asked about the presence of family members in the house only at the age of ten. Hence we do not know whether they lived with their mother or father before or after that age. However, the mother effect disappears when standard errors are clustered by country and birth period, suggesting that the loss of a parent could be related to the differential intensity of the war over time and place, or because the national policies aimed at protecting citizens against the war were not similarly effective across countries and years.
} 
With respect to hunger, additional evidence supporting this conclusion comes from the distribution of conditional trust (i.e. the predicted values of trust from the regression in column 1 of Table 5a) by hunger episodes and combat exposure. Hunger is associated with low trust for respondents exposed and non-exposed to WW2, though more clearly for the second group (Figure A3A in Appendix). This evidence suggests the war effects on trust cannot be completely explained by hunger. ${ }^{16} \mathrm{~A}$ similar comparison by father absence (Figure A3B in Appendix) does not highlight significant differences in trust by combat exposure. This finding supports the conclusion that father absence is not the key pathway from war to trust.

\subsection{Migration and dispossession as possible channels}

Our sample includes individuals who have never moved to other regions during WW2. This strategy delivers a rather homogenous sample since it excludes respondents who might have decided to move for unobserved reasons that might be correlated with combat exposure and trust. However, the estimated war effect could still be biased since most cities, like those in Germany, were deserted after massive bombings. Furthermore, forced relocations were very frequent during WW2 since entire neighbourhoods were destroyed by aerial attacks and also because of border changes and ethnic or political persecution in most European regions. It is therefore likely that relocations might have influenced the formation of social preferences through, for instance, the change in the network providing social support to the child (e.g. change in the family situation) or because the sudden movement to a new housing, financial and schooling environment might have influenced the cognitive and non-cognitive development of the child.

To test whether migration can explain the negative effects of WW2 on trust we construct a dummy variable for respondents who moved to another region in the period 1939$1945,{ }^{17}$ and include also these individuals in our econometric analysis. In Appendix (Section 1) we discuss and show that measurement error is not a severe problem. We also highlight that the candidate channels through which migration could influence trust

\footnotetext{
${ }^{16}$ Consistent with this finding, the interaction of combat exposure and hunger episode in an additional regression model is not statistically significant (available upon request).

17 The third wave of our SHARE dataset (SHARELIFE) asks each respondent the year when she has changed region of residence from the birthdate to the date of interview. Our migration variable is a $(0 / 1)$ dummy taking value one if the respondent has changed region of residence during the war period at least once.
} 
are number of family members and cognitive outcomes in childhood (see Appendix, Section 1). War-induced relocation seems to have negatively influenced social support, whereas it is positively associated with childhood cognitive outcomes, probably because of the better schooling and housing environment in the region of destination (or because of the worse conditions witnessed by those who remained in the war-affected areas).

Acknowledging potential endogeneity of relocation choices, we nonetheless re-estimate the specification in column 3 of Table 3 including also respondents who moved during the war period. Results are shown in Table 5a. The first column shows that the migration dummy is not statistically significant and does not absorb the war effect. Results in the second column show that the interaction between war and migration is not statistically significant. These findings suggest that migration played neither a mediating nor a moderating role in the association between war and trust. To check whether this is due to sample heterogeneity in the aforementioned childhood dimensions, we include as additional regressors the number of people living in the household (column 3), the number of rooms in the house (column 4), and the first factor capturing poor cognitive performance at the age of ten (column 5). None of these factors absorb the war effect, thereby leading us to the exclude migration as main explanation to our results.

As an additional consequence of war, frequent dispossessions of property - mostly driven by persecution - might have affected family composition, housing conditions and relocation decisions, with effects on trust similar to those hypothesized for migration. To explore this possible channel, we rely on self-reported dispossession episodes. More specifically, SHARELIFE respondents are asked whether (and when) they or their family were ever dispossessed of any property as a result of war or persecution. Also in this case, measurement error due to misreporting could be an issue. We deal with this in Appendix (Section 1), where we provide evidence suggesting that recall bias due to our cohort restriction or misreporting does not represent a major concern.

Regression estimates controlling for whether respondents were ever dispossessed confirm this last result (Table 5b), and suggest that dispossession might not be the main driver of our findings. Similar results are obtained when considering dispossessions occurred only during WW2 (available upon request). 


\subsection{The effect of WW2 on voluntary work}

We re-estimate the specifications with all controls in Table 3-4 (columns 3-4) replacing the attitudinal trust measure with a dummy variable equal to one if the respondent reports to have carried out voluntary or charity work in the last month (as asked in wave two) or year (as asked in wave five). This measure has been widely used as a proxy for other-regarding preferences and social capital (e.g. Putnam 1993; Glaeser et al. 2000), and it would capture individual characteristics underlying social engagement. The adverse effect of combat exposure remains significant also with this alternative dependent variable (Table A3a in Appendix), ${ }^{18}$ thereby supporting our hypothesis that violent conflicts generate long-run negative impacts on a broad set of attitudes and preferences that are associated with collective action.

We also look at whether combat exposure affected political participation, which could act as an additional (though different) proxy for social capital. Consistent with Grosjean (2014), we do find a positive effect on the likelihood that a respondent is engaged in political activities (binary measure proxying for political participation). However, the effect is not statistically significant in our OLS estimates (Table A3b in Appendix). ${ }^{19}$ Consider, however, that our respondents' average age is 67; thus, it is not surprising to find that only $5 \%$ of respondents in our sample are engaged in political activities, whereas this percentage rises to $19 \%$ for voluntary work.

\subsection{The heterogenous effects of WW2 on trust: coalitions and different types of episodes}

In this section, we investigate between-country heterogeneities in the effect of combat exposure. ${ }^{20}$ We first inspect whether the war effect changes whether someone belonged to the group of war winners or losers. We categorize the countries in our sample as

\footnotetext{
18 Given the binary nature of voluntary/charity work we also estimate this new model with a logistic regression. Results - available on request - are consistent with the OLS results.

${ }^{19}$ Logistic regressions (available upon request) produce similar results.

${ }^{20}$ Country regressions are not ideal because of the large number of period of birth and region dummies required by our identification strategy ---adequate statistical power cannot be reachable with the data at our disposal. We estimate, instead, a regression model testing heterogeneity in combat exposure by country in a more parsimonious way (and with larger statistical power). More specifically, we re-estimate the models in columns 1 and 3 in Table 2 and replace region with country fixed effects; hence we interact the country dummies with the war indicator. Results suggest that for most countries in our dataset the war has a negative impact on trust (though not always statistically significant); consistent with Kesternich et al. (2018), only for Germany combat exposure has a positive effect (results available upon request). However, these estimates do not account for within-country heterogeneity in trust and combat exposure, which is instead captured in our models including region fixed effects. In this paper, we also collect many channels of exposure and look deeper into the effect of war on trust.
} 
'winners' or 'losers' according to the Paris conference held in 1946. We therefore create three main categories, i.e. i) 'losers', including Germany, Austria and Italy; ii) 'winners', including France, Poland, Denmark, Greece, Belgium and Czech Rep.); and iii) 'no war', which is the left-out category including Sweden, Spain and Switzerland. We therefore split our war indicator into three categories, i.e. i) no war (omitted); ii) exposed to war, in winning side; iii) exposed to war, in losing side. Region fixed effects absorb the coalition effects for non-exposed respondents. We re-estimate models in Table 3 by using the new war variable. Results, reported in Table A4 in Appendix, show that the war effect is significant especially for respondents in the winning coalition, yet the interaction terms are not statistically different from each other. Hence, the war effect does not seem to change significantly across war coalitions.

Moreover, we go deeper into the type of war episodes respondents have been exposed to by differentiating combat exposure across different types of episodes. More specifically, we split the war indicator in four categories, i.e. i) no war (not exposed), ii) bombing (exposed to aerial attacks), iii) attack (exposed to a ground attack), iv) capture (exposed to a ground attack, which ends with surrender). We re-estimate our baseline model in Table 4 and find that the war effect is mainly driven by respondents exposed to capture events (Table 6). Speculating on the meaning of this novel result, one can argue that bombing attacks consisted of a war strategy aimed to destroy enemy soldiers and military bases, and happened often in low densely populated places. While bombings were certainly the most intense events, they were by their nature perceived as transitional and geographically located to a restricted area. On the other hand, city captures and surrenders episodes, although less intense, occurred at the end of a series of aerial and/or land attacks and consisted of local armies being imprisoned and local territory being governed by strangers. While bombings could be psychologically associated with luck or nature (and related to risk as shown by Kim and Lee 2014 and Bellucci et al. 2019), captures might involve interacting with strangers (the 'aggressors'), often in a subordinate position. Surrender episodes could be also more directly related to increased stress of respondent' parents when dealing with other people during the occupation, and hence to the intergenerational transmission of the belief that strangers could not be trusted. 


\subsection{The heterogenous effects of WW2 on trust: combat exposure by age cohorts}

Since the classification of war-related episodes could be subject to a certain degree of discretionality, ${ }^{21}$ we test whether our results hold when using a different dataset containing WW2 events by region. We rely on the data used by Kesternich et al. (2014), which allows us also to check whether the effect of WW2 on trust stems prevalently from exposure to combat operations in the first six years of life - a crucial period for the formation of trust attitudes as suggested by the aforementioned psychological research. To this purpose, we build on the strategy followed by Kesternich et al. (2014) and assess if combat exposure at different ages in childhood affect trust in later life. More specifically, we extend the sample to individuals born before 1939 and compare the effects of combat exposure across two main age groups (i.e. 0-6 and 7+). ${ }^{22}$ Even using a different dataset on WW2 episodes, regression results confirm our main results and also show that the war effect is stronger and statistically significant for respondents aged 0-6 during the war operations (Table 7), both at the extensive (columns 1-4) and intensive margin (columns 5-8).

In an additional check, we re-estimate the Kesternich et al. (2014)'s specification on respondents born between Sept. 1945 and Aug. 1957, and consider them as exposed if they were born in a region that experienced at least one war operation during the WW2 period. Regression results show that growing up in a war region affects later levels of trust for neither the $1945 / 9-1951 / 8$ age-cohorts $(\beta=-0.13 ; z=-0.94 ; p=0.347)$ nor the $1951 / 9-1957 / 8$ age-cohorts $(\beta=-0.01 ; z=-0.06 ; p=0.952) .{ }^{23}$ These findings suggest that parents who witnessed WW2 did not transmit their traumas to children born after the war, and hence the conflict, on average, did not persistently modify parental attitudes.

\footnotetext{
${ }^{21}$ The recording of war events may be subject to slightly different interpretations, e.g. regarding the region where an event occurred or the type of the event. For instance, a war episode occurred along a border river is not univocally attributable to a single region; or a war episode occurred in an area that now belongs to different countries (e.g., Prussia is today a part of eight different countries) is not univocally attributable to a single region. Similarly, many war events were military advances and artillery movements, which might not be considered as war events in a more parsimonious classification.

${ }^{22}$ Notice that identification in the new estimates rests only on between-region variation in war episodes, and not also on the within-region variation in respondents' month-year of birth (as in the previous estimates).

${ }^{23}$ OLS regressions are run using the Kesternich et al. (2014) dataset on WW2 and include year-of-birth, wave and country dummies as well as two dummies for age-cohorts 1945/9-1951/8 and 1951/9-1957/8 born in a region that experienced at least one WW2 episode. Standard errors clustered by year of birth and country. The inclusion of controls as in Table 7 does not change the main findings. Results are available upon request.
} 
Even if parents revised their trust upward or downward according to personal experiences of cooperation or conflict during and after WW2, in our data such an update does not seem to pass on to children born after the war. ${ }^{24}$

Thus, a likely mechanism underlying the WW2 effect is the stress witnessed during conflict episodes by the parents, who instilled in their children the perception of an insecure attachment bond and inconstant caregiving. As highlighted in Section 2, the psychological literature deems these two factors crucial for the formation of trust at early stages of life.

\subsection{Magnitude, robustness checks and summary}

With respect to the magnitude, on average being exposed to at least one conflict episode in the childhood decreases trust by 4-5 percent depending on the chosen specification. Similarly, the probability of carrying out voluntary/charity work when exposed to war early in life is 6.3 percentage points lower than when not exposed. These effects are sizeable considering for instance that exposure to combat when the respondent was six years old occurred 44 to 65 years before the survey. Consider also that the trust effect of being in the top vis-à-vis the bottom income percentile (a well-established determinant of trust) as measured at the date of interview is about 5 percent, i.e. a magnitude similar to the estimated impact of combat exposure.

Additional robustness checks reported in Appendix (Section 2) show that the estimated effect of WW2 exposure is robust to i) placebo tests run in the time-windows without real WW2 events; ii) different ways of clustering standard errors; iii) ordered-probit regressions accounting for the ordered nature of the dependent variable; iv) the inclusion of macro-level factors connected to WW2 such as per capita GDP, the share of victims during the war period, or the number of civilian and military deaths; v) the inclusion of respondents born before or after the WW2 time-window.

In spite of the documented consistency between historical facts and self-reported experiences of hunger, dispossession and parental absence (see Appendix, Section 1), the lack of a significant mediation role of such pathways from combat exposure to trust

\footnotetext{
${ }^{24}$ Additional robustness tests expanding our baseline sample to respondents born before or after the WW2 period are discussed in Appendix (Section 2).
} 
can still be due to selection in memory. To exclude this concern, we re-run the main analysis controlling for an alternative proxy for individual-level victimization during WW2, i.e. the first extracted factor from a PCA on a set of indicators for hunger, financial and psychological hardships during WW2. The method is described in details in Appendix (Section 3). Results, confirm the lack of a mediating and moderating role of the new subjective measures of victimization in the association between combat exposure and trust. Overall this piece of evidence, jointly with the proven consistency between historical and self-reported facts, suggests that the non-results when looking at hunger, dispossession and parental absence is not due to selection in memory or measurement error, but rather to the fact that the effect of combat exposure it is not accounted for by experience of these hardships.

Summarizing, our results suggests that early exposure to WW2 has a negative and persistent impact on trust. This impact does not seem to be driven by childhood factors related to war including health, malnutrition, parental absence, relocation and dispossession or to the SES of the family of origin. The estimated effect of WW2 on trust is fairly robust in magnitude and remains statistically significant when controlling for a wide set of childhood and adulthood characteristics. Since most self-reported episodes related to WW2 match with historical facts and with results from other studies including older cohorts, we also exclude that measurement error makes retrospective information irrelevant in explaining the war gap in trust. We also find that childhood SES and presence of mother at the age of ten positively predict trust in adulthood, even controlling for a large set of socio-economic and health outcomes. Additional estimates suggest that, consistent with the psychological literature, the effect of war is mainly driven by individuals born during WW2. A deeper investigation into the types of war events shows as well that surrender episodes following the capture of a city are the main driver of the persistent impact of WW2 exposure on trust.

\section{Selection}

In spite of the large set of robustness checks run in the previous section, the WW2 effect can still be driven by the respondents' self-selection in our sample because of differential out-of-sample migration, endogenous fertility, and selective mortality. 
Although with the data at our disposal it is difficult to assess the characteristics of individuals who are not in the sample, we show that our results cannot be entirely explained by these sources of endogeneity.

First, migration would lead us to overestimate the effect of WW2 if respondents with high SES - which is positively associated with trust - had also higher chances to move to non-war places than low-SES respondents. High-SES individuals, for instance, could have exploited their influential connections with visa officials in the home country and relied on personal networks in the destination countries. In addition, they had larger financial resources at their disposal and presumably good knowledge of foreign languages, which made migration smoother and increased job opportunities in the destination country. However, Kesternich et al. (2014) show evidence that outmigration during and after the war (1939-1947) was far to be easy. Using their data, we estimated that around 778,000 individuals migrated out of the countries in our sample, while 2,455,000 individuals moved in. In other words, for one person moving out, roughly three persons moved in. ${ }^{25}$ This figure has two main implications. First, those entering the countries where SHARE was administered are likely tracked by our analysis, and migration to other regions for these respondents does not play a major role (Table 5a). Second, if high-SES/high-trust respondents were more likely to migrate, high-SES/high-trust people should be overrepresented in our sample. Therefore, negative selection due to out-migration would be more than compensated by inmigration, thus leading to an underestimation rather than an overestimation of the true effect of the war.

Second, fertility decisions during WW2 could have been affected by war events. For instance, mothers who anticipated war episodes could have postponed childbirth to non-war periods. If fertility control in Europe during WW2 was, reasonably, more frequent among high-status classes, high-SES/high-trust respondents would have been underrepresented in our sample, thereby generating an upward bias. To have clues on whether fertility systematically differs by SES, we compare the average number of

\footnotetext{
${ }^{25}$ What is left out from the migration data provided by Kesternich et al. (2014) is the number of people who moved to the United States. We do not believe this is a crucial omission as migration to the US from the 1920 s to 1965 was at its minimum levels due to the quantitative restrictions, which imposed a ceiling on the number of immigrants accepted each year.
} 
respondents' siblings at the age of ten before, during and after WW2, and by SES at the age of ten (Table A16 in Appendix). This comparison shows that there are no remarkable differences in number of siblings over the considered periods, with both the high- and low-SES households displaying a marginally decreasing trend. This evidence is consistent with the fertility analysis carried out by Kesternich et al. (2014) on the same sample (SHARELIFE).

Furthermore, we re-estimate the models in column 3 of Tables 3-4 checking for the heterogeneous impact of WW2 by war period. It seems reasonable to assume that fertility adjustment might have not taken place during the initial phases of WW2, when parents could not perfectly forecast the timing and location of conflict episodes. Hence if fertility played a role, we would have overestimated the effect of the war especially for respondents born well after the outbreak of WW2. During the final stages of WW2, it might have been likely for high-SES/high-trust parents to postpone childbearing, not ultimately because conflict episodes occurred more frequently or less unexpectedly. However, Table A17 in Appendix shows no differential effects of combat exposure among those born before 1940 or 1941 and those born after, i.e. when war episodes were more predictable.

As an additional check for endogenous fertility, Figure A7A in Appendix displays the average number of months of WW2 exposure by SES in the childhood and by conception periods of the respondents. We compare exposed respondents conceived up to one month before the first war-episode (CB) with those of respondents conceived afterwards (CA). For parents of the CB group the first WW2-event was realistically more unpredictable than it was for the parents of the CA group, which includes respondents conceived when WW2 already reached the region. If there was a fertility adjustment driven by parental SES (and trust), we should have observed a significant difference in exposure between these two groups. More specifically, relative to the CB group, respondents conceived when WW2 episodes were predictable (e.g. after the first conflict in the region) should be less exposed to WW2 if their parents adjusted fertility according to the dynamics of the war. However, the Figure A7A displays no significant differences in terms of months of exposure between those conceived before and those conceived after the first war event, neither within the high-SES group (HS) nor within the low-SES group (LS). 
All these checks jointly considered suggest that our results are not entirely explained by endogenous fertility decisions.

Comparing the CA and the CB group by their average trust levels leads to two additional considerations (Figure A7B in Appendix). First, selective out-migration - potentially driven by high-SES/high-trust parents leaving their regions of residence in response to WW2 episodes - does not entirely drive our results. If this was the case, we should have observed significantly different trust levels between CA and CB respondents in the highSES group. However, Figure A7B in Appendix provides little support to this hypothesis. Second, it seems that the effect of combat exposure is not driven by mothers' stress or health problems during pregnancy (i.e. 'in-utero' exposure). By construction, mothers of the CA group were exposed to WW2 episodes for a longer period during pregnancy than their counterparts in the CB group. If WW2 affected respondents' trust when they were 'in utero', we would have found a significant difference in trust between the CA and CB group. Again, Figure A7B in Appendix shows that this is not the case. This is not surprising since, drawing from the literature on the 'fetal origin' hypothesis, adverse environmental circumstances before and immediately after the birth would negatively affect mental and physical health (De Rooij et al. 2010; Berg et al. 2016) as well as socioeconomic indicators (Almond and Currie 2011) in adult life. Most regressions in this paper include childhood and adulthood proxies for health and socio-economic status, which should therefore account for the indirect effects of 'in utero' exposure to combat, i.e. pre-natal stress that affect preferences through health outcomes of the children. These controls would also account for a possible epigenetic explanation to the persistent effect of combat exposure, i.e. the idea that a trauma can leave a chemical mark on a person's genes, which then is passed down to subsequent generations. For instance, children who were exposed in the womb to the Dutch Hunger Winter have been found to carry an enduring chemical mark on their genes, which has been associated higherthan-average body mass and hearth diseases later in life (Painter et al. 2006; Heijmans et al. 2008). However, our estimates are robust to the inclusion of many proxies for socio-economic status and health in childhood and in adulthood, thereby excluding that the epigenetic transmission of WW2 passes through respondents' health in childhood and adult life. Apart from health and socio-economic status, to the best of our 
knowledge, no other relevant channels of transmission of pre-natal stress into trust levels in adulthood have been highlighted in the literature.

Finally, mortality does not seem to be a major concern. If war-driven mortality was higher for low-SES individuals (whose trust would have been lower anyway), the WW2 effect we estimate could be considered as a lower bound of the real effect. To further exclude this unobserved source of selection, Kesternich et al. (2014) compare the age of death of the SHARE participants' father by i) SES, ii) living in war vs. non-war countries, and iii) year of birth (before 1946 or after 1945). Since no significant differences were found, they conclude that selection on mortality is not large enough to drive the gap in the later outcomes they consider. Consistent with these results, Havari and Peracchi (2016) provide evidence of low levels of childhood mortality during WW2 even in war countries. They also show that mortality at later ages was not systematically higher for those born during the war.

\section{Conclusion}

Violent conflicts in the last two centuries have been followed by diverging paths of institutional recovery, with quality of governance varying across countries affected and non-affected by combat episodes. A potential driver of this diversity stems from the change in the levels of social capital witnessed by societies exposed to major warfare. Previous research, mostly carried out on a single country and on a short time window after the war, has offered inconsistent evidence on whether social capital is harnessed or hampered by violent conflicts. While the focus has been on the short or medium-term effects, the legacies of war on trust and social capital could well persist over a person's entire life. In addition, the effects of conflict on social outcomes may also vary by country. Hence what are the long-run effects of a conflict affecting diverse socioeconomic and institutional contexts on social preferences is still an open issue.

This paper provides an answer to this question by evaluating the long-term legacies of a large-scale conflict on trust across individuals who happened to be in their pre-school age during the Second World War. By using changes in places and timing of combats in Europe, we identify the effect of early exposure to WW2 on trust, both at the intensive 
and extensive margin, and controlling for period and region fixed effects. Our results document that early-life exposure to combat decreases trust in adulthood by five percent, and generates a 6.3 percentage-points drop in the probability of future social engagement.

These findings confirm results from most psychological studies emphasizing that early childhood is a critical period for the formation of trust, and an age where combat exposure may persist throughout life. Pre-school children form trust in others prevalently through the interaction with their parents, and responsive childcare might nurture positive expectations about the surrounding world. Traumatic experiences and parents' reactions to distressing events could have adversely affected the formation of children's trust and their beliefs about the trustworthiness of others, with long-term consequences on social preferences. In other words, exposure to violence may have set children on a low path for trust development through the anxiety intentionally or unintentionally exhibited by parents in response to acts of war.

Importantly, we found that the effect of war does not change when accounting for several societal and individual factors including current and childhood socio-economic status, episodes of hunger and dispossession during the war, absence of father and number of deaths during WW2. Among childhood characteristics, SES and mother's presence positively predict trust, even though these factors do not mediate nor moderate the impact of war on trust. Lack of a mediating effect of parental absence should not be necessarily exclude transmission of anxiety and irresponsive childcare as possible explanations to the war-effect on trust. First, parental absence is measured at the age of ten (i.e. after the war), and it can therefore be considered as an imprecise proxy for quality of childcare during the war. For instance, some respondents could have witnessed the loss of a parent after the end of the war, while others could have been born orphans. Second, this measure would not account for the dynamic transmission of stress mirroring the evolution of WW2-operations. Conditional of having both parents, differential anxiety of parents (or irresponsive childcare) could still emerge, e.g. from the inner characteristics of the WW2 episodes, and vary during war. 
In facts, results are mainly driven by exposure to city-captures (ending with surrender) and, in line with the psychological literature, they are stronger for respondents exposed at pre-school age. Furthermore, they are not entirely driven by selection in memory, differential migration, endogenous fertility and selective mortality. While our findings suggest that the war effect is not due to socio-economic conditions in childhood nor to a change in parental values, but most likely to the stress and anxiety of parents every time a conflict event occurred, further research is needed to pin down the exact psychological mechanisms underlying the estimated impact. For instance, our data do not contain information on the respondent's parents. However, additional estimates document that combat exposure increases respondents' detachment from their own family in adulthood, as proxied for by contacts with children (see Section 4 in Appendix). This piece of evidence further highlights that the likely mechanism behind our finding is the insecure attachment bond and/or inconstant caregiving witnessed during WW2.

Unfortunately, while measurement error and recall bias are not key in our analysis, we are not able to identify whether the WW2 effect is driven by the induced awareness of being a 'child of war' or by transmission of parental stress. Respondents experiencing war episodes might have been socialized to think of themselves as different from nonexposed respondents. ${ }^{26}$ Nevertheless, if induced awareness is independent from length of exposure (e.g. it does not change dramatically whether a child experienced two or ten months of conflict), our measure of exposure at the intensive margin should not be subject to this sort of bias.

Our empirical evidence is in line with previous studies documenting that violence can increase the 'bonding' rather than the 'bridging' component of trust. More specifically, Grosjean (2014) shows that exposure to conflict reduces generalized trust and increases collective action, 'but of a kind that is associated with the erosion of social and political trust' (Grosjean 2014, p. 426). Combining our negative results for voluntary work and trust with the non-significant (yet positive) results for political engagement, our findings in general suggest that exposure to WW2 produced a decline in the 'bridging' dimension of trust. Such a decline may reflect the 'dark' side of political and social capital (Grosjean 2014), i.e. the aspect of social capital that relates to the 'bonding' effects of repeated interactions. This is also consistent with other experimental results documenting that

\footnotetext{
${ }^{26}$ We thank an anonymous referee for raising this issue.
} 
the conflict experience fosters 'bonding' rather than 'bridging' social capital (e.g. Cassar et al. 2013) as well as with other empirical results underlining the role of civic associations in the collapse of democracy in interwar Germany (Satyanath et al. 2017).

The meta-study conducted by Bauer et al. (2016) documents a positive and persistent association between war and pro-social preferences. However, higher post-conflict prosociality emerges only among individuals sharing the same ethnic, political or national identity, with intra-group cooperation stemming from the search for a common identity, though at the cost of eroding inter-group social capital. Hence the increase in in-group favouritism and out-group hostility (i.e. 'parochial altruism') spurred by conflict is in line with the decrease in generalized trust, i.e. trust in others in general independently from group affiliation, which we found in our data. Furthermore, our results confirm and extend to a lifetime perspective previous experimental (Cassar et al. 2013; Becchetti et al. 2014) and survey (Dercon et al. 2012; Rohner et al. 2013) evidence documenting that violence, by stimulating trust and cooperation only among members of the same group, erodes generalized trust and hinders the formation of 'bridging' social capital and inter-ethnic cooperation, which might lead to the outbreak of new inter-group conflicts. Hence the increase in in-group favouritism and out-group hostility (i.e. 'parochial altruism') spurred by conflict is, again, consistent with the decrease in generalized trust as measured by the generalized trust question in our data, i.e. trust in others in general, independently from group affiliation.

Relatedly, Delhey et al. (2011) show that answers to the generalized trust question across many societies predominantly connotes out-group trust, thereby suggesting that our attitudinal measure of trust would capture out- rather than in-group trust. Thus, the negative effect of WW2 exposure is not necessary in contrast with previous studies showing, instead, that violence increases prosociality. Such an increase would relate to parochialism, and may come at a cost of reducing trust towards generalized others.

Concluding, exposure to combat at early age may have a negative impact on trust and social engagement, which are two important pillars of cooperation in social dilemma. Our findings provide robust evidence that for infants a war is forever.

In the light of the well-established association between trust, collective action and quality of governance, traumatic events witnessed by the 'children of war' might 
adversely influence the type of society these children will live in when they become adults.

\section{Data disclaimer}

This paper uses data from SHARE Waves 2, 3 (SHARELIFE) and 5, see Börsch-Supan et al. (2013) for methodological details. The SHARE data collection has been primarily funded by the European Commission through FP5 (QLK6-CT-2001-00360), FP6 (SHARE-I3: RII-CT-2006062193, COMPARE: CIT5-CT-2005-028857, SHARELIFE: CIT4-CT-2006-028812) and FP7 (SHARE-PREP: $\mathrm{N}^{\circ} 211909$, SHARE-LEAP: $\mathrm{N}^{\circ} 227822$, SHARE M4: ํ261982). Additional funding from the German Ministry of Education and Research, the Max Planck Society for the Advancement of Science, the U.S. National Institute on Aging (U01_AG09740-13S2, P01_AG005842, P01_AG08291, P30_AG12815, R21_AG025169, Y1-AG-4553-01, IAG_BSR06-11, OGHA_04-064, HHSN271201300071C) and from various national funding sources is gratefully acknowledged (see www.share-project.org). 


\section{References}

Aboud, F. E. (2003). The formation of in-group favoritism and out-group prejudice in young children: Are they distinct attitudes?. Developmental psychology, 39(1), 48.

Ainsworth, M. S., \& Bowlby, J. (1991). An ethological approach to personality development. American psychologist, 46(4), 333.

Akbulut-Yuksel, M. (2014). Children of War The Long-Run Effects of Large-Scale Physical Destruction and Warfare on Children. Journal of Human Resources, 49(3), 634-662.

Akresh, R., Bhalotra, S., Leone, M., \& Osili, U. O. (2012). War and stature: Growing up during the Nigerian civil war. American Economic Review, 102(3), 273-77.

Algan, Y., \& Cahuc, P. (2010). Inherited trust and growth. American Economic Review, 100(5), 2060-2092.

Allport, G. W. (1961), Pattern and Growth in Personality. New York, Holt, Rinehart and Winston.

Almond, D., \& Currie, J. (2011). Killing me softly: The fetal origins hypothesis. Journal of economic perspectives, 25(3), 153-72.

Arpino, B., Conzo, P., \& Salustri, F. (2019). I'm a survivor, keep on surviving: Early-life exposure to conflict and subjective survival probabilities in adult life (No. 201904). University of Turin.

Arroyo, W., \& Eth, S. (1996). Traumatic stress reactions and post- traumatic stress disorder (PTSD). In R. Apfel \& B. Simon (Eds.), Minefields in the heart: The mental health of children in war and communal violence. New Haven, CT: Yale University Press.

Barber, B. K. (2009). Making sense and no sense of war: Issues of identity and meaning in adolescents' experience with political conflict. In B. K. Barber (Ed.), Adolescents and war: How youth deal with political violence (pp. 281-311). New York, NY, US: Oxford University Press.

Bauer, M., Blattman, C., Chytilová, J., Henrich, J., Miguel, E., \& Mitts, T. (2016). Can war foster cooperation?. The Journal of Economic Perspectives, 30(3), 249-274.

Bauer, M., Cassar, A., Chytilová, J., \& Henrich, J. (2014a). War's enduring effects on the development of egalitarian motivations and in-group biases. Psychological science, 25(1), 47-57.

Bauer, M., Chytilová, J., \& Pertold-Gebicka, B. (2014b). Parental background and other-regarding preferences in children. Experimental Economics, 17(1), 24-46.

Bauer, M., Fiala, N. \& Levely, I. (2017). Trusting Former Rebels: An Experimental Approach to Understanding Reintegration after Civil War. Economic Journal, forth.

Becchetti, L., Conzo, P., \& Romeo, A. (2014). Violence, trust, and trustworthiness: evidence from a Nairobi slum. Oxford Economic Papers, 66(1).

Bellows, J., \& Miguel, E. (2006). War and institutions: New evidence from Sierra Leone. American Economic Review, 96(2), 394-399.

Bellows, J., \& Miguel, E. (2009). War and local collective action in Sierra Leone. Journal of Public economics, 93(11), 1144-1157.

Bellucci, D., Fuochi, G., \& Conzo, P. (2019). Childhood exposure to the Second World War and financial risk taking in adult life. Journal of Economic Psychology, 102196. 
Berg, G. J., Pinger, P. R., \& Schoch, J. (2016). Instrumental variable estimation of the causal effect of hunger early in life on health later in life. The Economic Journal, 126(591), 465-506.

Berg, J., Dickhaut, J., \& McCabe, K. (1995). Trust, reciprocity, and social history. Games and economic behavior, 10(1), 122-142.

Blattman, C. (2009). From violence to voting: War and political participation in Uganda. American political Science review, 103(2), 231-247.

Blattman, C., \& Miguel, E. (2010). Civil war. Journal of Economic literature, 48(1), 3-57.

Bowlby, J. (1979). The Making \& Breaking of Affectional Bonds, Psychology Press.

Bundervoet T., Verwimp P., and Akresh R. (2009), Health and civil war in rural Burundi. Journal of Human Resources, 44: 536-563.

Burlingham, D., \& Freud, A. (1942). Young children in war-time in a residential war nursery. Allen \& Unwin for the New Era.

Carmil, D., \& Breznitz, S. (1991). Personal Trauma and World View-Are extremely stressful experiences related to political attitudes, religious beliefs, and future orientation?. Journal of Traumatic stress, 4(3), 393-405.

Cassar, A., Grosjean, P., \& Whitt, S. (2013). Legacies of violence: trust and market development. Journal of Economic Growth, 18(3), 285-318.

Cattell, R. B. (1965). The Scientific Analysis of Personality. Baltimore, Penguin Books.

Child, T. B., \& Nikolova, E. (2016). War and Social Attitudes: Revisiting Consensus Views. Available at SSRN: https://ssrn.com/abstract=2817856.

Collier, P. (2004). The Second World War (4). The Mediterranean 1940-1945 Oxford: Osprey Publishing.

Collier, P., \& World Bank. (2003). Breaking the conflict trap: Civil war and development policy. Washington, DC: Worid Bank

Conzo, P., Aassve, A., Fuochi, G., \& Mencarini, L. (2017). The cultural foundations of happiness. Journal of Economic Psychology, 62, 268-283.

Crain, W. (2005). Theories of development: Concepts and applications. Upper Saddle River, NJ: Pearson Prentice Hall.

Cunha, F., \& Heckman, J. (2007). The technology of skill formation. American Economic Review, 97(2), 31-47.

Currie, J., \& Vogl, T. (2013). Early-life health and adult circumstance in developing countries. Annu. Rev. Econ., 5(1), 1-36.

Davies N. (2006). No Simple Victory: World War II in Europe, 1939-1945, Viking Press.

Davis, D. R., \& Weinstein, D. E. (2002). Bones, bombs, and break points: the geography of economic activity. American Economic Review, 92(5), 1269-1289.

De Juan, A., \& Pierskalla, J. H. (2016). Civil war violence and political trust: Microlevel evidence from Nepal. Conflict Management and Peace Science, 33(1), 67-88. 
De Rooij, S. R., Wouters, H., Yonker, J. E., Painter, R. C., \& Roseboom, T. J. (2010). Prenatal undernutrition and cognitive function in late adulthood. Proceedings of the National Academy of Sciences, 107(39), 16881-16886.

Dercon, S., \& Gutiérrez-Romero, R. (2012). Triggers and characteristics of the 2007 Kenyan electoral violence. World Development, 40(4), 731-744.

Dohmen, T., Falk, A., Huffman, D., \& Uwe Sunde (2012). The Intergenerational Transmission of Risk and Trust Attitudes. The Review of Economic Studies, 79(2), 645-677.

Eisenberg, N., Fabes, R. A., \& Spinrad, T. L. (2006). Handbook of child psychology.

Ellis J. (1994), World War II. A Statistical Survey, Aurum Press.

Erikson, E. H. (1950), Childhood and Society. New York, Norton.

Erikson, E. H. (1959). Identity and the life cycle. Psychological Issues, 1(1), 18-164.

Fehr, E. (2009). On the economics and biology of trust, The Journal of the European Economic Association, 7(2-3), 235-266.

Fehr, E., Bernhard, H., \& Rockenbach, B. (2008). Egalitarianism in young children. Nature, 454(7208), 1079.

Forstmeier, S., Kuwert, P., Spitzer, C., Freyberger, H. J., \& Maercker, A. (2009). Posttraumatic growth, social acknowledgment as survivors, and sense of coherence in former German child soldiers of World War II. The American Journal of Geriatric Psychiatry 17(12), 10301039.

Frey, B. S., \& Meier, S. (2004). Social comparisons and pro-social behavior: Testing" conditional cooperation" in a field experiment. American Economic Review, 94(5), 1717-1722.

Gächter, S., Herrmann, B., \& Thöni, C. (2004). Trust, voluntary cooperation, and socio-economic background: survey and experimental evidence.Journal of Economic Behavior \& Organization, 55(4), 505-531.

Gilligan, M. J., Pasquale, B. J., \& Samii, C. (2014). Civil war and social cohesion: Lab-in-the-field evidence from Nepal. American Journal of Political Science, 58(3), 604-619.

Glaeser, E. L., Laibson, D. I., Scheinkman, J. A., \& Soutter, C. L. (2000). Measuring trust. The Quarterly Journal of Economics, 115(3), 811-846.

Glaesmer, H., Brähler, E., Gündel, H., \& Riedel-Heller, S. (2011). The association of traumatic experiences and posttrautmatic stress disorder with physical morbidity in old age: A German population based study. Psychosomatic Medicine, 73, 359.

Grosjean, P. (2014). Conflict and social and political preferences: Evidence from World War II and civil conflict in 35 European countries. Comparative Economic Studies, 56(3), 424-451.

Hardin, R. (2004). Trust and Trustworthiness. Russel Sage Foundation, New York.

Hardt, J., \& Rutter, M. (2004). Validity of adult retrospective reports of adverse childhood experiences: review of the evidence. Journal of child psychology and psychiatry, 45(2), 260273.

Havari, E. and Peracchi F. (2016). Growing up in wartime: Evidence from the era of two world wars. Economics \& Human Biology, 25, 9-32. 
Havari, E., and Mazzonna F. (2015), Can we trust older people's statements on their childhood circumstances? Evidence from SHARELIFE. European Journal of Population, 33: 233-257.

Heckman, J., Pinto, R., \& Savelyev, P. (2013). Understanding the mechanisms through which an influential early childhood program boosted adult outcomes.American Economic Review, 103(6), 2052-86.

Heijmans, B. T., Tobi, E. W., Stein, A. D., Putter, H., Blauw, G. J., Susser, E. S., ... \& Lumey, L. H. (2008). Persistent epigenetic differences associated with prenatal exposure to famine in humans. Proceedings of the National Academy of Sciences, 105(44), 17046-17049.

Ichino A., and Winter-Ebmer R. (2004), The long-run educational cost of World War Two. Journal of Labor Economics, 22, 57-86.

Kesternich I., Siflinger B., Smith J.P., and Winter J. (2014), The effects of World War II on economic and health outcomes across Europe. Review of Economics and Statistics, 96, 103118.

Kesternich, I., Siflinger, B., Smith, J. P., \& Winter, J. (2015). Individual Behaviour as a Pathway between Early - life Shocks and Adult Health: Evidence from Hunger Episodes in Post war Germany. The Economic Journal, 125(588).

Kesternich, I., Smith, J. P., Winter, J. K., \& Hörl, M. (2018). Early - Life Circumstances Predict Measures of Trust among Adults: Evidence from Hunger Episodes in Post - War Germany. The Scandinavian Journal of Economics.

Kijewski, S., \& Freitag, M. (2016). Civil War and the Formation of Social Trust in Kosovo Posttraumatic Growth or War-related Distress?.Journal of Conflict Resolution, 0022002716666324.

Kim, Y. I., \& Lee, J. (2014). The long-run impact of a traumatic experience on risk aversion. Journal of Economic Behavior \& Organization, 108, 174-186.

La Porta R., Lopez-de-Silane F., Shleifer A. and Vishny R.W. (1997). Trust in Large Organizations. American Economic Review, 87(2): 333-338.

Leon, G. (2012). Civil conflict and human capital accumulation the long-term effects of political violence in perú. Journal of Human Resources, 47(4), 991-1022.

Maddison, A. (2011), Historical statistics: Statistics on World population, GDP and per capita GDP, 1-2008. Available at http://www.ggdc.net /MADDISON/oriindex.htm.

Masten, A. S. (2001). Ordinary magic: Resilience processes in development. American psychologist, 56(3), 227.

Miguel, E., \& Roland, G. (2011). The long-run impact of bombing Vietnam. Journal of development Economics, 96(1), 1-15.

Murtin, F., Fleischer, L., Siegerink, V., Aassve, A., Algan, Y., Boarini, R., ... \& Kim, S. (2018), "Trust and its determinants: Evidence from the Trustlab experiment", OECD Statistics Working Papers, No. 2018/02, OECD Publishing, Paris, https://doi.org/10.1787/869ef2ec-en.

OECD (2017), OECD Guidelines on Measuring Trust, OECD Publishing, Paris, https://doi.org/10.1787/9789264278219-en. 
Ostrom, E. (2000). Collective action and the evolution of social norms. Journal of economic perspectives, 14(3), 137-158.

Overman, R. (1999), Deutsche Militaerische Verluste im 2 Weltkrieg, Munich: Oldenburg Verlag.

Painter, R. C., de Rooij, S. R., Bossuyt, P. M., Simmers, T. A., Osmond, C., Barker, D. J., ... \& Roseboom, T. J. (2006). Early onset of coronary artery disease after prenatal exposure to the Dutch famine-. The American journal of clinical nutrition, 84(2), 322-327.

Punamäki, R. L., Qouta, S., \& El Sarraj, E. (1997). Relationships between traumatic events, children's gender, and political activity, and perceptions of parenting styles. International Journal of Behavioral Development, 21(1), 91-109

Putnam, R. (1993). Making democracy work: Civic traditions in modern Italy. Princeton University Press.

Putnam, R. D., Feldstein, L., \& Cohen, D. J. (2004). Better together: Restoring the American community. Simon and Schuster.

Putzger, F.W. (1963). Historischer Weltatlas, Biele felid: Velhagen \& Klasing.

Pynoos, R. \& Nader, K. (1993). Issues in the treatment of posttraumatic stress disorder in children and adolescents. In: Wilson, J., Raphael, B. (eds). International Handbook of Traumatic Stress Syndromes. NYC: Plenum Press, 535-549.

Rohner, D., Thoenig, M., \& Zilibotti, F. (2013). Seeds of distrust: Conflict in Uganda. Journal of Economic Growth, 18(3), 217-252.

Rondinelli, D. A. (2007). The Challenges of Restoring Governance in Crisis and Post-Conflict Countries. United Nations, New York, USA

Rosenberg, M. (1956). Misanthropy and political ideology. American Sociological Review, 21, 690-5.

Sapienza, P., Toldra, A. \& Zingales, L. (2013) Understanding Trust. The Economic Journal. Volume 123(573), 1313-1332.

Satyanath, S., Voigtländer, N., \& Voth, H. J. (2017). Bowling for fascism: Social capital and the rise of the Nazi Party. Journal of Political Economy, 125(2), 478-526.

Scholz, J. T., \& Lubell, M. (1998). Trust and taxpaying: Testing the heuristic approach to collective action. American Journal of Political Science, 398-417.

Statistisches Jahrbuch für das Deutsche Reich (Statistical Yearbook), Kaiserliches Statistisches Amt, Berlin: Puttkammer \& Meuhlbrecht, 1909-1939.

Tabellini, G. (2010). Culture and institutions: Economic development in the regions of Europe. Journal of the European Economic Association, 8, 677-716.

Tamis-LeMonda, C. S., Shannon, J. D., Cabrera, N. J., \& Lamb, M. E. (2004). Fathers and mothers at play with their 2-and 3-year-olds: contributions to language and cognitive development. Child development, 75(6), 1806-1820.

Tilly, C., \& Ardant, G. (1975). The formation of national states in Western Europe (Vol. 8). Princeton University Press.

Uslaner E. M. (1999). Democracy and social capital. In M. Warren (Ed.), Democracy and Trust (pp. 121-150). Cambridge, Cambridge University Press. 
Uslaner, E. M. (2002). The Moral Foundations of Trust. New York, Cambridge University Press.

Van den Berg, G. J., Pinger, P. R., \& Schoch, J. (2016). Instrumental variable estimation of the causal effect of hunger early in life on health later in life. The Economic Journal, 126(591), 465-506.

Van Mourik, W. (1978), Bilanz des Krieges. Rotterdam: Lekturama.

Voigtländer, N., \& Voth, H. J. (2015). Nazi indoctrination and anti-Semitic beliefs in Germany. Proceedings of the National Academy of Sciences, 112(26), 7931-7936.

Volken, T. (2002). Elements of trust: The cultural dimension of Internet diffusion revisited. Electronic Journal of Sociology, 6(4), 1-20.

Voors, M. J., \& Bulte, E. H. (2014). Conflict and the evolution of institutions: Unbundling institutions at the local level in Burundi. Journal of Peace Research, 51(4), 455-469.

Voors, M. J., Nillesen, E. E., Verwimp, P., Bulte, E. H., Lensink, R., \& Van Soest, D. P. (2012). Violent conflict and behavior: a field experiment in Burundi. American Economic Review, 102(2), 941-64.

Waters, E., Heinicke, C. M., \& Bretherton, I. (1995). Caregiving, cultural, and cognitive perspectives on secure-base behavior and working models: New growing points of attachment theory and research. University of Chicago Press.

Werner, E. E. (2007). Resilience and protective factors in the lives of individuals who were children and youths in World War II. In I. Fooken \& J. Zinnecker (Eds.), Trauma und Resilienz (pp. 47-55). Munich: Juventa Verlag.

Werner, E. E. (2012). Children and war: Risk, resilience, and recovery. Development and psychopathology, 24(2), 553-558. 
Figure 1 - Examples of within-region time variation in exposure to WW2

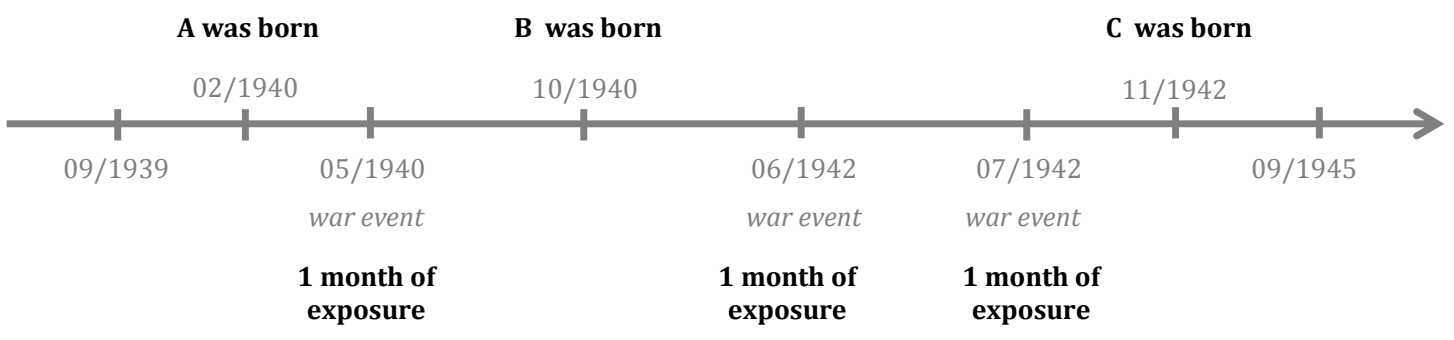

Figure 2 - Socio-economic status during childhood and exposure to WW2

$A$

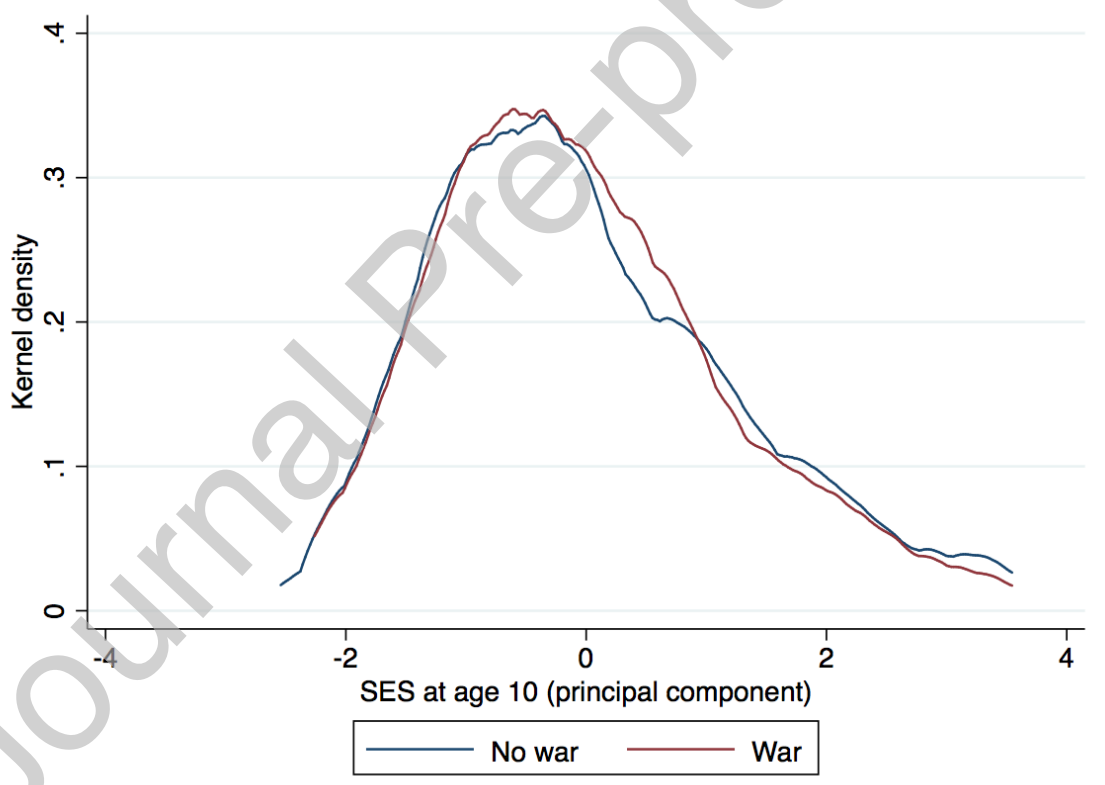


B

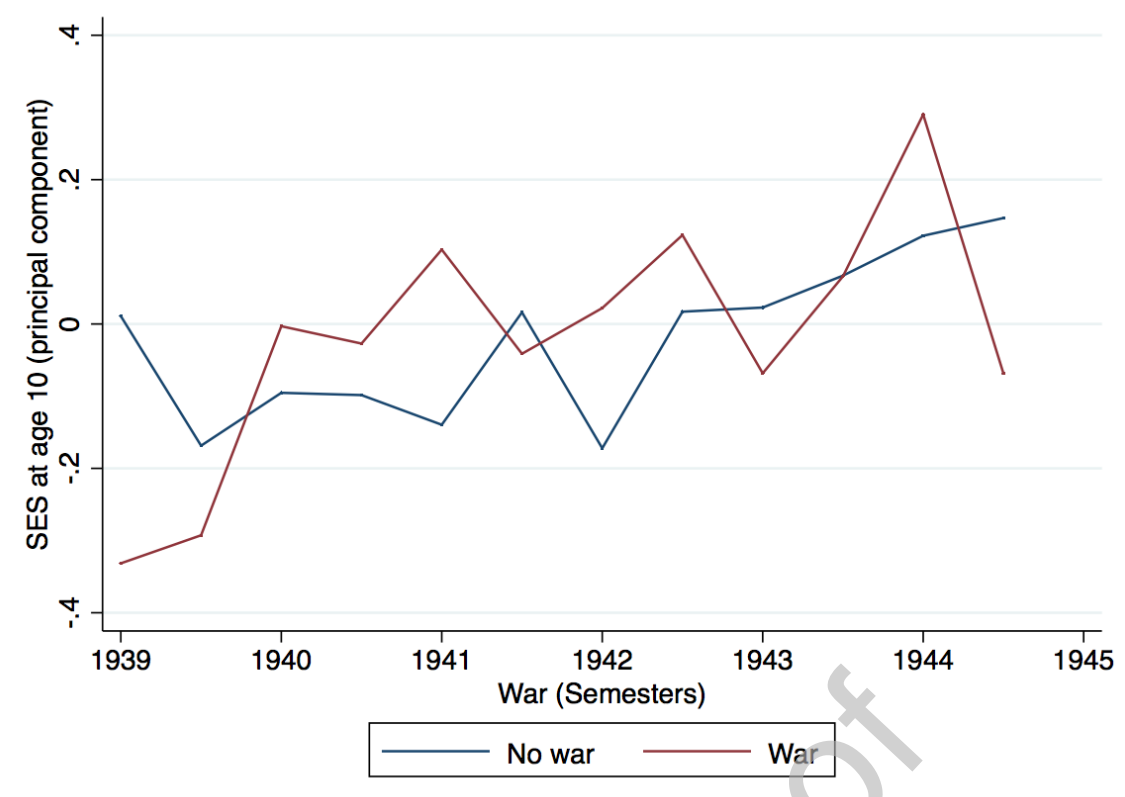


Figure 3 - Average trust by WW2-exposure

A
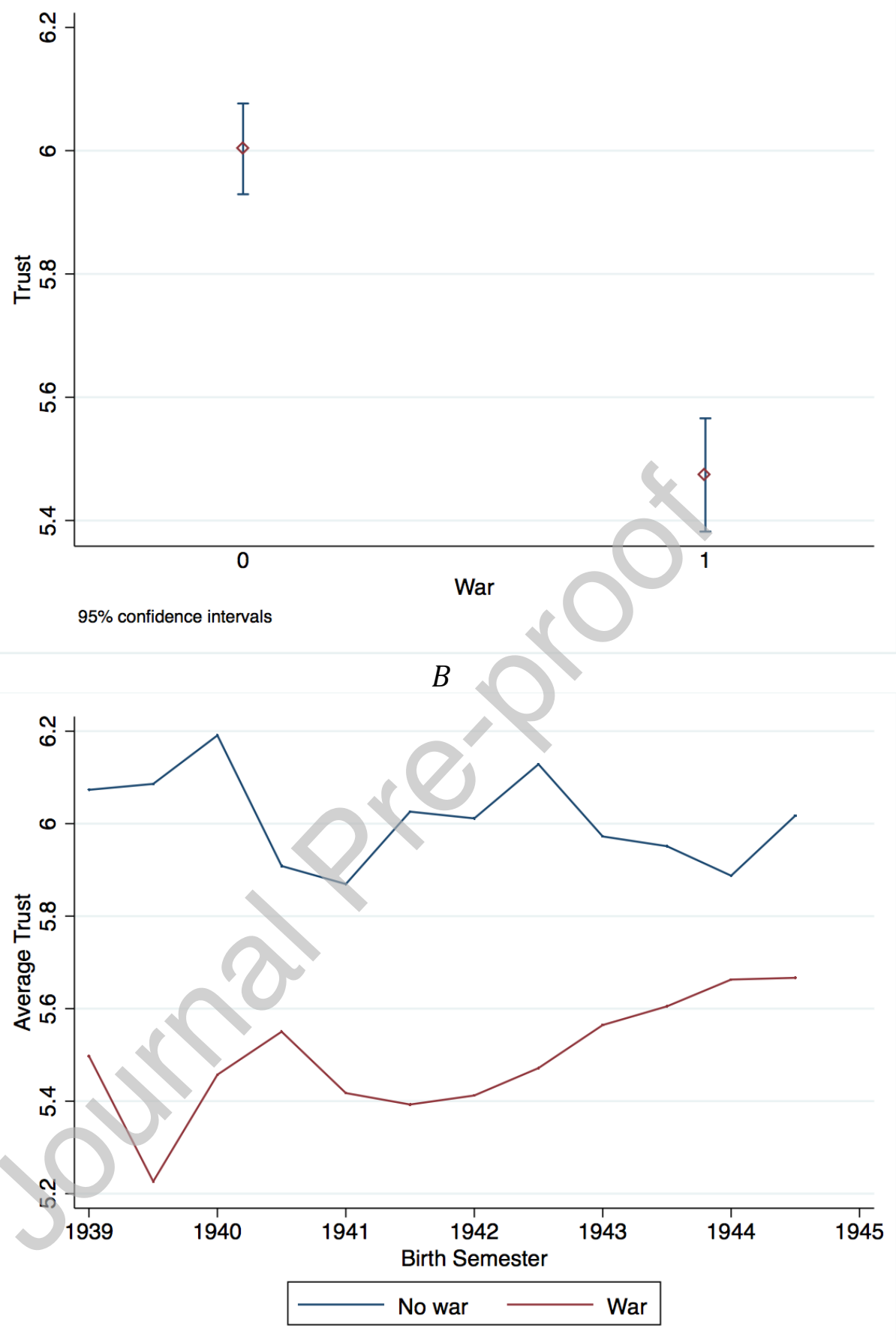
Figure 4 - Regional distribution of war episodes and exposed people during WW2 $A$

War Events in Europe

World War II Database

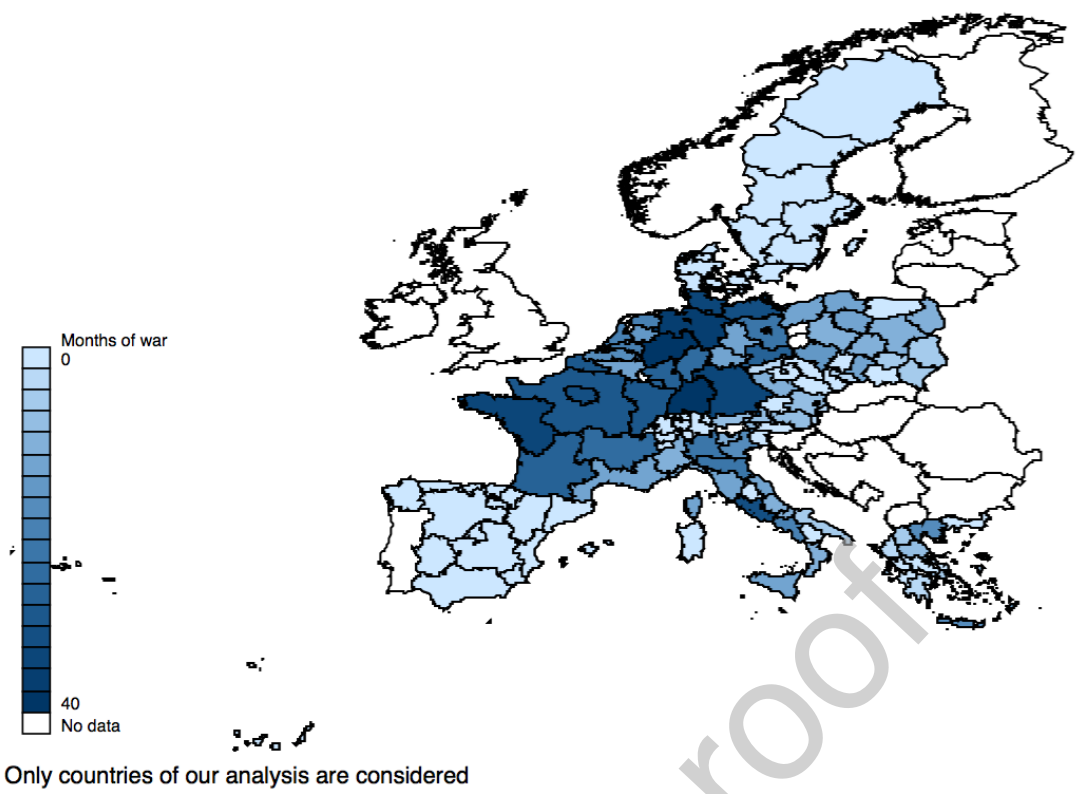

$B$

War Events in Europe

Percentage of exposed

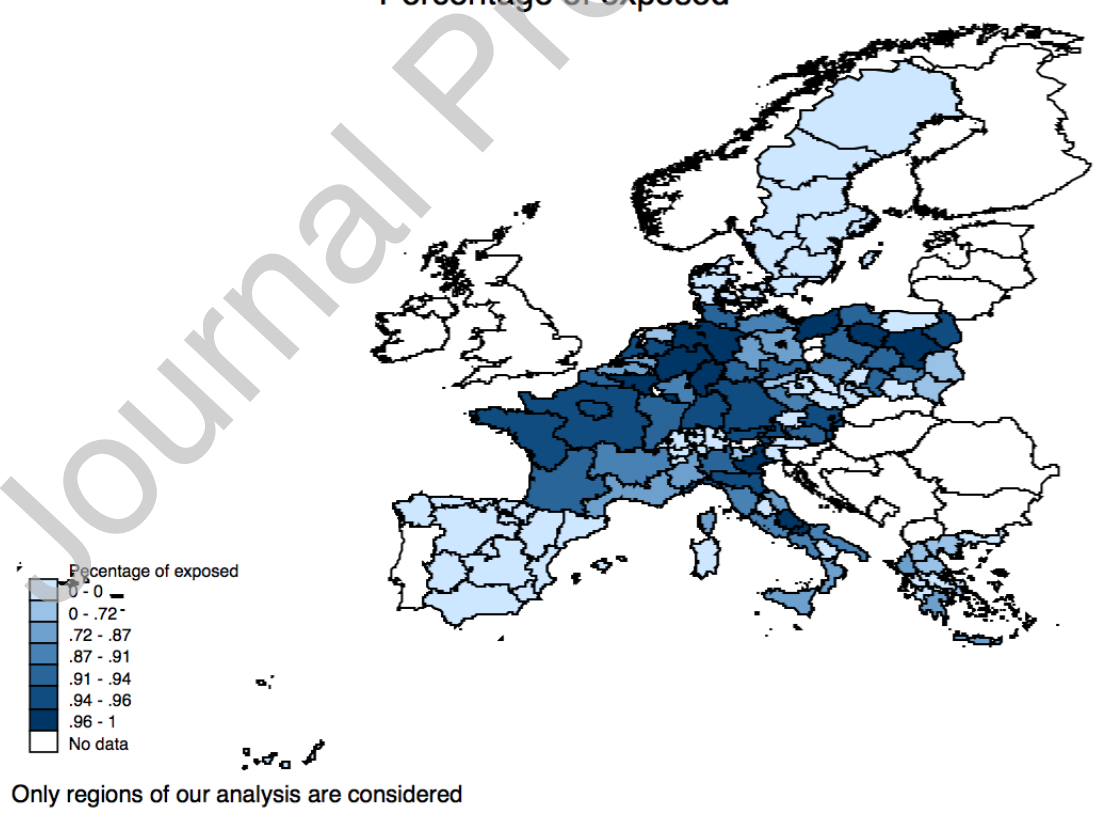


Table 1 - Descriptive Statistics

\begin{tabular}{|c|c|c|c|c|c|}
\hline Variable & Obs & Mean & Std. Dev. & Min & Max \\
\hline Trust & 6,759 & 5.80 & 2.423 & 0 & 10 \\
\hline Voluntary/Charity work & 6,738 & 0.19 & 0.397 & 0 & 1 \\
\hline Political engagement & 6,571 & 0.05 & 0.22 & 0 & 1 \\
\hline War $(0-1)$ & 6,759 & 0.39 & 0.488 & 0 & 1 \\
\hline \multicolumn{6}{|l|}{ War (0-2) } \\
\hline $0=0$ months of exposure (no war) & 6,759 & 0.61 & 0.49 & 0 & 1 \\
\hline $1=1-3$ months of exposure & 6,759 & 0.19 & 0.19 & 0 & 1 \\
\hline $2=4+$ months of exposure & 6,759 & 0.20 & 0.19 & 0 & 1 \\
\hline Bombing & 6,759 & 0.17 & 0.38 & 0 & 1 \\
\hline Attack & 6,759 & 0.11 & 0.36 & 0 & 1 \\
\hline Capture & 6,759 & 0.32 & 0.46 & 0 & 1 \\
\hline SES in childhood (PCA, first extracted component) & 6,439 & $1.59 \mathrm{e}^{-9}$ & 1.25 & -2.54 & 3.58 \\
\hline \multicolumn{6}{|l|}{ Year of birth } \\
\hline 1939 & 6,759 & 0.05 & 0.208 & 0 & 1 \\
\hline 1940 & 6,759 & 0.16 & 0.362 & 0 & 1 \\
\hline 1941 & 6,759 & 0.14 & 0.347 & 0 & 1 \\
\hline 1942 & 6,759 & 0.16 & 0.367 & 0 & 1 \\
\hline 1943 & 6,759 & 0.17 & 0.377 & 0 & 1 \\
\hline 1944 & 6,759 & 0.19 & 0.395 & 0 & 1 \\
\hline 1945 & 6,759 & 0.13 & 0.340 & 0 & 1 \\
\hline Female & 6,759 & 0.54 & 0.498 & 0 & 1 \\
\hline \multicolumn{6}{|l|}{ Marital status } \\
\hline Married and living together with spouse & 6,756 & 0.75 & 0.435 & 0 & 1 \\
\hline Registered partnership & 6,756 & 0.01 & 0.121 & 0 & 1 \\
\hline Married, living separated from spouse & 6,756 & 0.02 & 0.122 & 0 & 1 \\
\hline Never married & 6,756 & 0.05 & 0.210 & 0 & 1 \\
\hline Divorced & 6,756 & 0.07 & 0.252 & 0 & 1 \\
\hline Nidowed & 6,756 & 0.10 & 0.311 & 0 & 1 \\
\hline \multicolumn{6}{|l|}{ Income percentile } \\
\hline 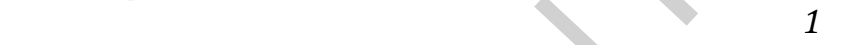 & 6,759 & 0.07 & 0.263 & 0 & 1 \\
\hline 2 & 6,759 & 0.09 & 0.281 & 0 & 1 \\
\hline 3 & 6,759 & 0.11 & 0.312 & 0 & 1 \\
\hline 4 & 6,759 & 0.11 & 0.315 & 0 & 1 \\
\hline 5 & 6,759 & 0.12 & 0.318 & 0 & 1 \\
\hline 6 & 6,759 & 0.11 & 0.316 & 0 & 1 \\
\hline 7 & 6,759 & 0.12 & 0.322 & 0 & 1 \\
\hline 8 & 6,759 & 0.10 & 0.299 & 0 & 1 \\
\hline 9 & 6,759 & 0.09 & 0.291 & 0 & 1 \\
\hline 10 & 6,759 & 0.08 & 0.271 & 0 & 1 \\
\hline Job Status & 6,729 & 0.73 & 0.443 & 0 & 1 \\
\hline Job (Employed, self-employed, Homemaker) & 6,729 & 0.23 & 0.423 & 0 & 1 \\
\hline No job (Unemployed, Sick or disabled) & 6,729 & 0.04 & 0.184 & 0 & 1 \\
\hline \multicolumn{6}{|l|}{ Education } \\
\hline None or Primary & 6,755 & 0.29 & 0.454 & 0 & 1 \\
\hline Lower Secondary & 6,755 & 0.20 & 0.395 & 0 & 1 \\
\hline Upper Secondary & 6,755 & 0.28 & 0.450 & 0 & 1 \\
\hline Tertiary & 6,755 & 0.23 & 0.423 & 0 & 1 \\
\hline Health functionalities & 6,759 & -0.18 & 1.449 & -0.92 & 12.48 \\
\hline Memory & 6,730 & 9.09 & 3.269 & 0 & 20 \\
\hline N. chronic diseases & 6,752 & 1.15 & 1.151 & 0 & 7 \\
\hline Hunger episode (during WW2) & 6,759 & 0.03 & 0.164 & 0 & 1 \\
\hline Mother at age $10(0=$ absent $)$ & 6,753 & 0.95 & 0.225 & 0 & 1 \\
\hline Father at age $10 \quad(0=$ absent $)$ & 6,753 & 0.87 & 0.334 & 0 & 1 \\
\hline Gdp (during WW2) & 5,332 & 17,42 & 7.523 & 6.8 & 39.97 \\
\hline Share of deaths (during WW2) & 6,568 & 0.03 & 0.036 & 0.000 & 0.167 \\
\hline
\end{tabular}


Civilian deaths (x 100,000)

Military deaths (x 100,000)

Moved during war

Ever dispossessed

No. of books

$\begin{array}{ccccc}6,586 & 3.00 & 7.968 & 0 & 32.5 \\ 6,586 & 3.75 & 8.806 & 0 & 31.7 \\ 7,683 & 0.12 & 0.325 & 0 & 1 \\ 6,749 & 0.03 & 0.172 & 0 & 1\end{array}$

$$
0-10
$$

6,707

0.43

11-25

26-100

6,707

101-200

6,707

6,707

$201+6,707$

0.22

0.22

0.07

0.06

0.495

0.413

0.414

0.254

0.243

No. of rooms

$\mathrm{N}$. people in household when 10

Language relative performance when 10

\section{Much better \\ Better}

About the same

Worse

6,703

6,711

3.69

5.50

2.093

2.211

6,602

0.11

0.26

6,602

6,602

6,602

0.50

0.13

0.315

0.437

0.500

0.340

Math relative performance when 10

Much better
Better

6,611

6,611

0.11

0.314

0.437

0.500

0.333

Worse

6,611

0.13

$6,559 \quad-0.01$

$6,702 \quad 0.04$

1,264

0.193

6,737

0.45

0.498

$\begin{array}{cc}-3.54 & 2.43 \\ 0 & 1 \\ 0 & 1\end{array}$

Health status when child

\section{Excellent \\ Good \\ Fair}

6,723

0.35

0.476

6,723

0.32

6,723

0.25

6,723

0.07

0.467

0.431

0.247

0.02

0.146

6,723

$2.70 \mathrm{e}^{-10}$

1.069

6,627

$-1.88 \mathrm{e}^{-8}$

1.212

$\begin{array}{cc}0 & 1 \\ 0 & 1 \\ 0 & 1 \\ 0 & 1 \\ 0 & 1 \\ -1.24 & 12.92 \\ -6.36 & 0.477\end{array}$

Wave

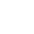

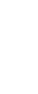

(n)


Table 2 - Combat exposure and trust

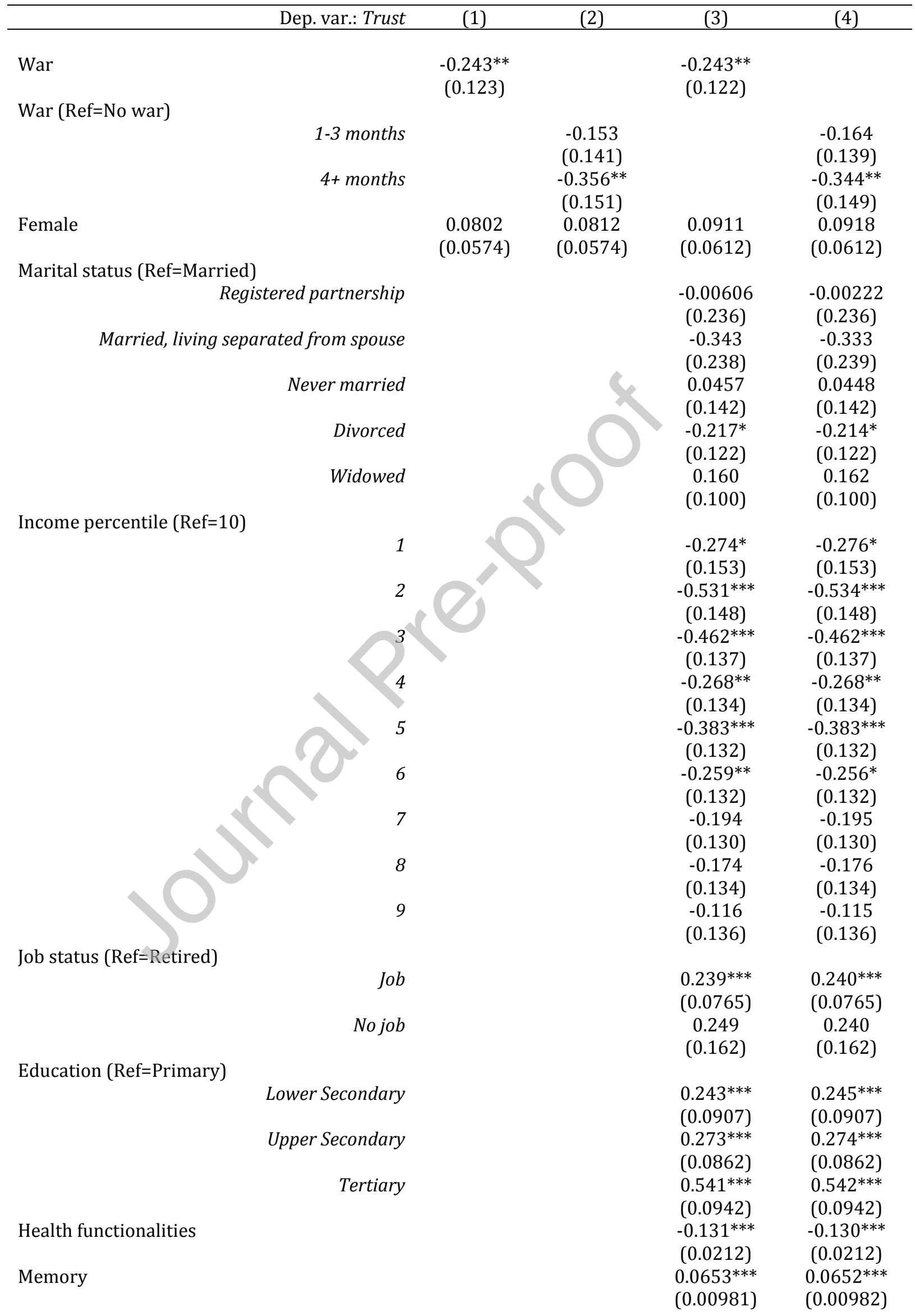




$\begin{array}{lcccc}\text { Wave } 5 & 0.210^{* * *} & 0.211^{* * *} & 0.327^{* * *} & 0.327^{* * *} \\ & (0.0596) & (0.0596) & (0.0621) & (0.0621) \\ \text { Constant } & 5.616^{* * *} & 5.519^{* * *} & 4.873^{* * *} & 4.789^{* * *} \\ & (0.490) & (0.496) & (0.499) & (0.504) \\ & \text { Yes } & \text { Yes } & \text { Yes } & \text { Yes } \\ \text { Month/Year of birth FE } & \text { Yes } & \text { Yes } & \text { Yes } & \text { Yes } \\ \text { Region FE } & & & & \\ & 6,555 & 6,555 & 6,494 & 6,494 \\ \text { Observations } & 0.157 & 0.157 & 0.189 & 0.189 \\ \text { R-squared } & & & & \end{array}$

pard errors in parentheses

*** $\mathrm{p}<0.01,{ }^{* *} \mathrm{p}<0.05,{ }^{*} \mathrm{p}<0.1$

Table 3 - Combat exposure and trust: the role of childhood SES

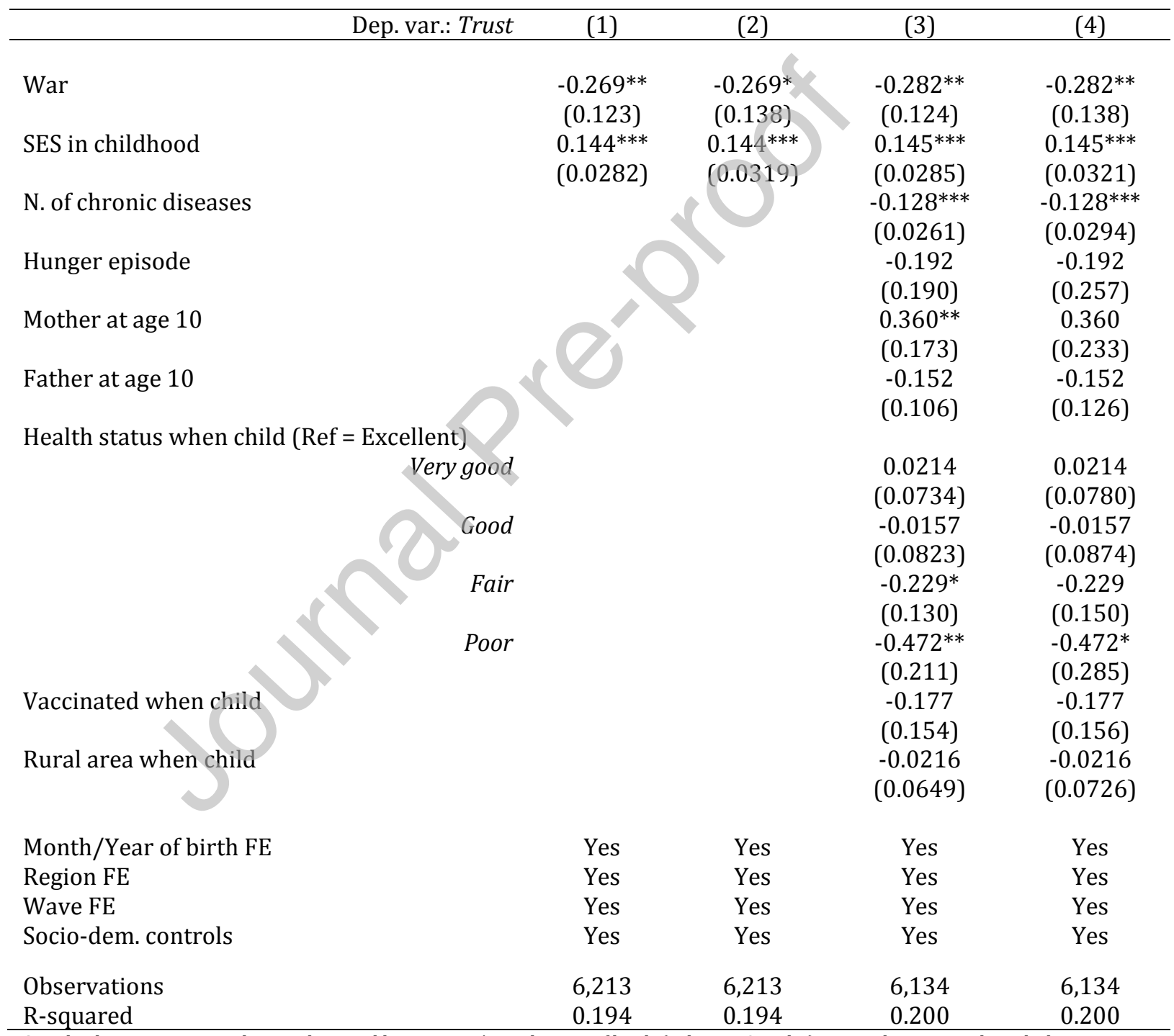

Standard errors in parentheses, clustered by country/month-year of birth (columns 2 and 4); socio-dem. controls include regressors in Table 2 (col. $3-4$ ); ${ }^{* * *} \mathrm{p}<0.01,{ }^{* *} \mathrm{p}<0.05{ }^{*} \mathrm{p}<0.1$. 
Table 4 - Combat exposure and trust: the role of childhood SES

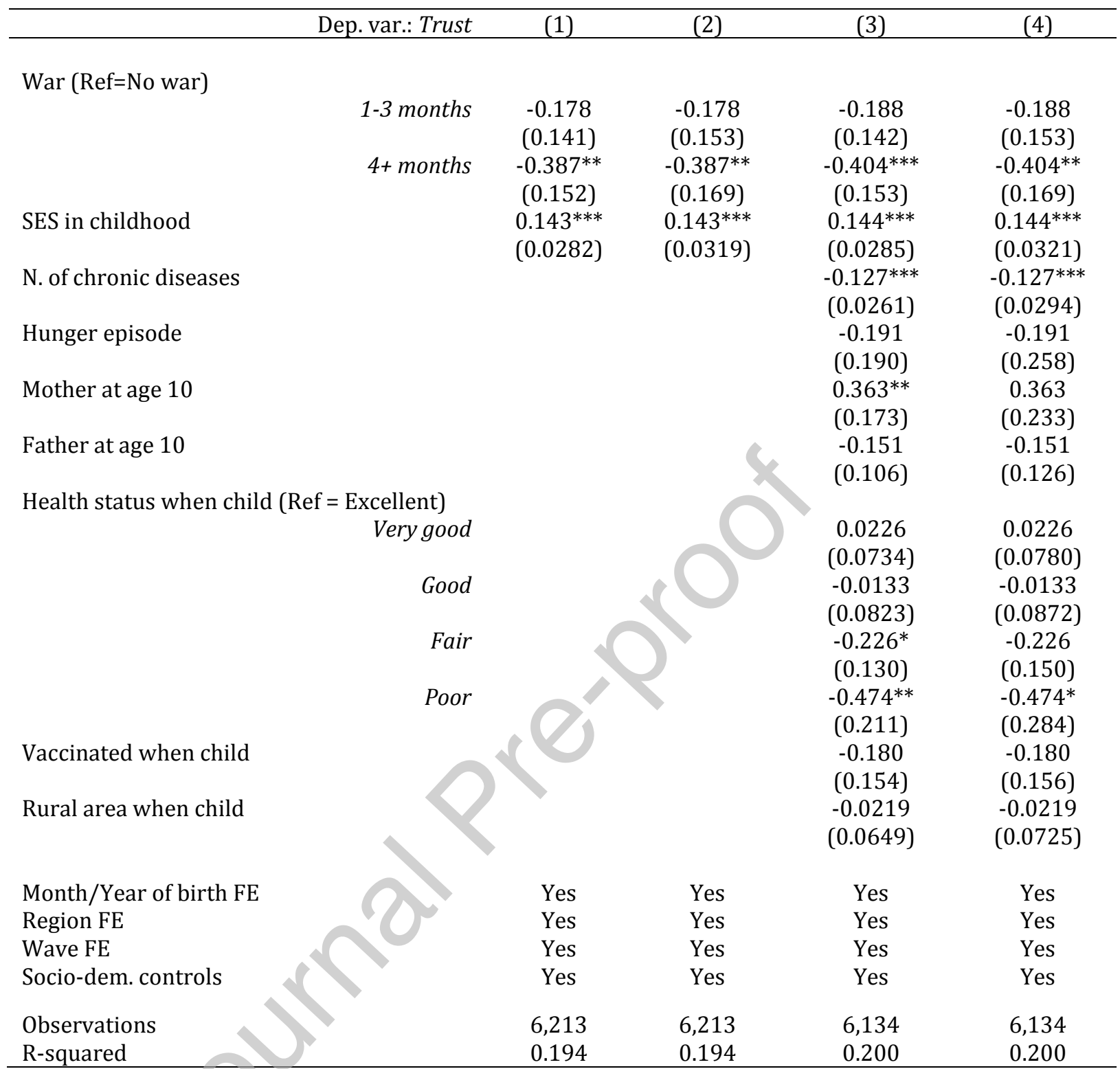

Standard errors in parentheses, clustered by country/month-year of birth (columns 2, 4); socio-dem. controls include regressors in Table 2 (col. 3-4); *** $\mathrm{p}<0.01,{ }^{* *} \mathrm{p}<0.05,{ }^{*} \mathrm{p}<0.1$. 
Table 5a - Combat exposure and trust: the migration channel

\begin{tabular}{|c|c|c|c|c|c|}
\hline Dep. var.: Trust & $(1)$ & $(2)$ & $(3)$ & $(4)$ & $(5)$ \\
\hline War & $\begin{array}{c}-0.271^{* *} \\
(0.119)\end{array}$ & $\begin{array}{c}-0.294^{* *} \\
(0.120)\end{array}$ & $\begin{array}{c}-0.253^{* *} \\
(0.118)\end{array}$ & $\begin{array}{c}-0.262^{* *} \\
(0.118)\end{array}$ & $\begin{array}{c}-0.244^{* *} \\
(0.119)\end{array}$ \\
\hline Moved during war & $\begin{array}{c}0.00131 \\
(0.0914)\end{array}$ & $\begin{array}{c}-0.102 \\
(0.126)\end{array}$ & $\begin{array}{c}0.00268 \\
(0.0894)\end{array}$ & $\begin{array}{c}0.0126 \\
(0.0898)\end{array}$ & $\begin{array}{c}-0.0141 \\
(0.0906)\end{array}$ \\
\hline War* Moved during war & & $\begin{array}{c}0.218 \\
(0.183)\end{array}$ & & & \\
\hline SES in childhood & $\begin{array}{c}0.124^{* * *} \\
(0.0267)\end{array}$ & $\begin{array}{l}0.123^{* * *} \\
(0.0267)\end{array}$ & & & \\
\hline N. people in household when 10 & & & $\begin{array}{c}0.0217 \\
(0.0136)\end{array}$ & $\begin{array}{c}0.0103 \\
(0.0143)\end{array}$ & $\begin{array}{c}0.0117 \\
(0.0146)\end{array}$ \\
\hline Rooms when ten years old & & & & $\begin{array}{c}0.0489^{* * *} \\
(0.0170)\end{array}$ & $\begin{array}{l}0.0434^{* *} \\
(0.0172)\end{array}$ \\
\hline Poor cognitive skills (first PCA factor) & & & & & $\begin{array}{c}-0.106^{* * *} \\
(0.0259)\end{array}$ \\
\hline Month/Year of birth FE & Yes & Yes & Yes & Yes & Yes \\
\hline Region FE & Yes & Yes & Yes & Yes & Yes \\
\hline Wave FE & Yes & Yes & Yes & Yes & Yes \\
\hline Socio-dem. \& childhood controls & Yes & Y & Yes & Yes & Yes \\
\hline Observations & 6,875 & 6,875 & 7,150 & 7,119 & 6,954 \\
\hline R-squared & 0.193 & 0.194 & 0.185 & 0.187 & 0.191 \\
\hline
\end{tabular}

Table 5b - Combat exposure and trust: the dispossession channel

\begin{tabular}{|c|c|c|c|c|c|}
\hline Dep. var.: Trust & (1) & $(2)$ & (3) & (4) & (5) \\
\hline War & $\begin{array}{c}-0.273^{* *} \\
(0.119)\end{array}$ & $\begin{array}{c}-0.282^{* *} \\
(0.119)\end{array}$ & $\begin{array}{c}-0.256^{* *} \\
(0.118)\end{array}$ & $\begin{array}{c}-0.265^{* *} \\
(0.118)\end{array}$ & $\begin{array}{c}-0.246^{* *} \\
(0.119)\end{array}$ \\
\hline Ever dispossessed & $\begin{array}{l}-0.0838 \\
(0.171)\end{array}$ & $\begin{array}{l}-0.280 \\
(0.246)\end{array}$ & $\begin{array}{l}-0.0366 \\
(0.169)\end{array}$ & $\begin{array}{l}-0.0501 \\
(0.170)\end{array}$ & $\begin{array}{l}-0.0612 \\
(0.170)\end{array}$ \\
\hline War*Ever disposse & & $\begin{array}{c}0.374 \\
(0.339)\end{array}$ & $\begin{array}{c}0.0219 \\
(0.0136)\end{array}$ & & \\
\hline SES in childhood & $\begin{array}{c}0.124^{* * *} \\
(0.0268)\end{array}$ & $\begin{array}{l}0.123^{* * *} \\
(0.0268)\end{array}$ & & & \\
\hline N. people in household when 10 & & & & $\begin{array}{c}0.0105 \\
(0.0143)\end{array}$ & $\begin{array}{c}0.0119 \\
(0.0146)\end{array}$ \\
\hline Rooms when ten years old & & & & $\begin{array}{l}0.0490^{* * *} \\
(0.0170)\end{array}$ & $\begin{array}{l}0.0437^{* *} \\
(0.0172)\end{array}$ \\
\hline Poor cognitive skills (first PCA factor) & & & & & $\begin{array}{l}-0.105^{* * *} \\
(0.0259)\end{array}$ \\
\hline Moved during war & $\begin{array}{l}0.00413 \\
(0.0915)\end{array}$ & $\begin{array}{l}0.00326 \\
(0.0915)\end{array}$ & $\begin{array}{l}0.00432 \\
(0.0894)\end{array}$ & $\begin{array}{c}0.0146 \\
(0.0898)\end{array}$ & $\begin{array}{c}-0.0116 \\
(0.0906)\end{array}$ \\
\hline Month/Year of birth FE & Yes & Yes & Yes & Yes & Yes \\
\hline Region FE & Yes & Yes & Yes & Yes & Yes \\
\hline Wave FE & Yes & Yes & Yes & Yes & Yes \\
\hline Socio-dem. \& childhood controls & Yes & Yes & Yes & Yes & Yes \\
\hline Observations & 6,873 & 6,873 & 7,148 & 7,117 & 6,952 \\
\hline R-squared & 0.193 & 0.194 & 0.185 & 0.187 & 0.191 \\
\hline
\end{tabular}


Table 6 - The heterogenous effects of WW2 on trust: different types of events

\section{(1)}

(2)

(3)

$(4)$

$\begin{array}{lcc}\text { Bombing } & -0.198 & -0.238 \\ & (0.220) & (0.221) \\ \text { Attack } & -0.109 & -0.126 \\ & (0.268) & (0.269) \\ \text { Capture } & -0.309^{* *} & -0.319^{* *} \\ & (0.151) & (0.151)\end{array}$

Bombing only

$(0.151)$

Attack or Capture

$(0.220)$
$-0.284^{* *}$
$(0.144)$

Capture only

$-0.362^{* *}$

$(0.180)$

$-0.203$

(0.157)

Month/Year of birth FE

Region FE

Wave FE

Socio-dem. controls

SES in childhood

Additional controls

Yes
Yes
Yes
Yes
Yes
No

6,213

0.199

R-squared

Standard errors in parentheses, clustered by country/month-year of birth; omitted category: no war; socio-dem. controls include regressors in Table 2 (columns 2 and 4); additional controls include: health status, hunger episode, mother at age 10, father at age 10 , health status when child, vaccinated when child, rural area when child; ${ }^{* * *} \mathrm{p}<0.01,{ }^{* *} \mathrm{p}<0.05,{ }^{*} \mathrm{p}<0.1$. 
Table 7 - Combat exposure across different age-groups and trust (Kesternich et al. 2014's dataset)

\begin{tabular}{|c|c|c|c|c|c|c|c|c|}
\hline Dep. Var.: Trust & $(1)$ & $(2)$ & (3) & $(4)$ & (5) & (6) & (7) & $(8)$ \\
\hline Exposed at age $0-6$ & $\begin{array}{l}-0.211^{* *} \\
(0.0887)\end{array}$ & $\begin{array}{l}-0.224^{* *} \\
(0.0889)\end{array}$ & $\begin{array}{l}-0.165^{*} \\
(0.0876)\end{array}$ & $\begin{array}{l}-0.178^{* *} \\
(0.0876)\end{array}$ & & & & \\
\hline Exposed at age 7+ & $\begin{array}{l}-0.122 \\
(0.111)\end{array}$ & $\begin{array}{l}-0.143 \\
(0.110)\end{array}$ & $\begin{array}{l}-0.117 \\
(0.109)\end{array}$ & $\begin{array}{l}-0.139 \\
(0.109)\end{array}$ & & & & \\
\hline Exposed at age $0-6 \& 7+$ & $\begin{array}{c}-0.337^{* *} \\
(0.135)\end{array}$ & & $\begin{array}{c}-0.325^{* *} \\
(0.134)\end{array}$ & & & & & \\
\hline $\begin{array}{l}\text { Exposed at age } 0-6 \& \\
0-3 \text { months of combats }\end{array}$ & & & & & $\begin{array}{l}-0.146^{*} \\
(0.0786)\end{array}$ & $\begin{array}{c}-0.111 \\
(0.0802)\end{array}$ & $\begin{array}{c}-0.117 \\
(0.0780)\end{array}$ & $\begin{array}{l}-0.0847 \\
(0.0800)\end{array}$ \\
\hline Exposed at age 0-6 \& & & & & & $-0.233^{* * *}$ & $-0.200^{* *}$ & $-0.206^{* * *}$ & $-0.178^{* *}$ \\
\hline 4-10 months of combats & & & & & $(0.0730)$ & $(0.0775)$ & $(0.0726)$ & $(0.0770)$ \\
\hline Exposed at age $7+\&$ & & & & & -0.0241 & -0.0213 & -0.0394 & -0.0348 \\
\hline 0-3 months of combats & & & & & $(0.103)$ & $(0.118)$ & $(0.101)$ & $(0.115)$ \\
\hline Exposed at age $7+\&$ & & & & & -0.141 & -0.120 & -0.153 & -0.133 \\
\hline 4-10 months of combats & & & & & $(0.0944)$ & $(0.0984)$ & $(0.0939)$ & $(0.0987)$ \\
\hline Controls & NO & NO & YES & YES & & NO & YES & YES \\
\hline Observations & 18,193 & 16,790 & 18,193 & 16,790 & 18,242 & 14,847 & 18,242 & 14,847 \\
\hline R-squared & 0.109 & 0.112 & 0.120 & 0.124 & 0.109 & 0.111 & 0.121 & 0.125 \\
\hline
\end{tabular}

Robust standard errors in parentheses clustered by year of birth and country. Only SHARE respondents (waves 2 and 5) born between 1908 and 1945. Controls include: education level, marital status, job status (missing values are flagged for these three variables), income percentile. Dummies for gender, wave, country and year of birth are included in all models. Columns 2, 4, 6 and 8 exclude individuals exposed to war events both at age 0-6 and 7+. Combat exposure is measured in terms of months of exposure to WW2 combats in the region when the respondent was in the period 1939-1945 as in Kesternich et al. (2014), ${ }^{* *} \mathrm{p}<0.01,{ }^{* *} \mathrm{p}<0.05,{ }^{*} \mathrm{p}<0.1$. 